1 Single-cell analyses of the corneal epithelium: Unique cell types 2 and gene expression profiles

3

4

5

6 Surabhi Sonam*,1, Sushant Bangru* ${ }^{*, 2,4}$, Kimberly J. Perry ${ }^{1}$, Auinash Kalsotra ${ }^{2,3,4}$,

7 Jonathan J. Henry ${ }^{1, \#}$

8

9 * Equal contribution

$10{ }^{1}$ Department of Cell and Developmental Biology, University of Illinois, Urbana-

11 Champaign, IL

122 Department of Biochemistry, University of Illinois, Urbana-Champaign, IL

$13{ }^{3}$ Carl R. Woese Institute for Genomic Biology, University of Illinois, Urbana-

14 Champaign, IL

154 Cancer Center@Illinois, University of Illinois, Urbana-Champaign, IL

16

\# Corresponding author: j-henry4@illinois.edu

\title{
21 KEYWORDS
}

22 Cornea

23 Single-cell RNA-sequencing

24 Xenopus

25 Stem cells

26 Differentiation

27 Biomarkers 


\section{SUMMARY STATEMENT}

36 This study identifies cell types and transcriptional heterogeneity in the corneal

37 epithelium that regulate its differentiation, and facilitates the search for corneal stem

38 cell markers.

\section{ABSTRACT}

41 Corneal Epithelial Stem Cells (CESCs) and their proliferative progeny, the Transit

42 Amplifying Cells (TACs), are responsible for homeostasis and maintaining corneal

43 transparency. Owing to our limited knowledge of cell fates and gene activity within

44 the cornea, the search for unique markers to identify and isolate these cells remains crucial for ocular surface reconstruction. We performed single-cell RNA sequencing

46 of corneal epithelial cells from stage 49-51 Xenopus larvae. We identified five main

47 clusters with distinct molecular signatures, which represent apical, basal and

48 keratocyte cell types as well as two discrete proliferative cell types in the bi-layered

49 epithelium. Our data reveal several novel genes expressed in corneal cells and spatiotemporal changes in gene expression during corneal differentiation. Through gene regulatory network analysis, we identified key developmental gene regulons, which guide these different cell states. Our study offers a detailed atlas of single-cell transcriptomes in the frog corneal epithelium. In future, this work will be useful to elucidate the function of novel genes in corneal homeostasis, wound healing and cornea regeneration, which includes lens regeneration in Xenopus. 


\section{INTRODUCTION}

The corneal epithelium is the outermost layer of the eye, and is essential for focusing light, maintaining normal vision and protecting deeper eye tissues. Owing to its constant exposure to the external environment, the corneal epithelial tissue has a remarkable capacity for self-renewal and repair, which is attributed to the presence of a population of somatic stem cells, called Corneal Epithelial Stem Cells (CESCs), and their proliferative progeny, the Transit Amplifying Cells (TACs). Therefore, the self-renewing corneal epithelium serves as an outstanding model to study the biology of epithelial stem cells, and their contributions to a highly specialized differentiated tissue.

The cellular composition and homeostatic maintenance of the corneal epithelium have been studied extensively (Cotsarelis et al., 1989; Di Girolamo, 2011; Lavker et al., 2004; Schermer et al., 1986; Thoft and Friend, 1983). In adult vertebrates, the stratified corneal epithelium consists of an innermost layer of undifferentiated basal cells, suprabasal cells, and differentiated, superficial (apical) squamous cells. Some studies in humans and mice (Amitai-Lange et al., 2015; Davanger and Evensen, 1971; Di Girolamo, 2011; Zhao et al., 2009) provide evidence that CESCs reside in the basal epithelium (in the specialized niche called the "limbus"). Contrary to this, other studies suggest that CESCs are distributed throughout the basal corneal epithelial layer (Chang et al., 2008; Majo et al., 2008). Despite some ambiguity about their location, it is known that these cells divide either symmetrically for stem cell renewal, or asymmetrically to produce more highly proliferative TACs that migrate centripetally to populate the corneal epithelium (Kinoshita et al., 1981; Tseng, 1989). As these TACs divide and migrate superficially, they progressively become more differentiated and eventually give rise to postmitotic, terminally differentiated cells (TDCs), which undergo senescence and are sloughed off from the surface. Despite the long known existence of CESCs and TACs among vertebrates, we are limited in our understanding of the comprehensive genetic profiles of these cells and the maturation of their differentiated progeny. This has largely affected the search for definitive molecular markers to identify, isolate and enrich corneal stem cells, which are used for clinical applications.

Several studies on transcriptional profiling of corneal epithelial cells isolated from humans and mice have relied on bulk-sampling techniques and cell enrichment 
using pre-defined markers (Bath et al., 2013; Ma and Lwigale, 2019; Sartaj et al., 2017; Zhou et al., 2006). As these studies were restricted to specific subpopulations or regions of the corneal epithelium, it has been difficult to compare findings across these studies and systematically analyze corneal epithelial heterogeneity. Therefore, to facilitate the search of corneal stem cell biomarkers, one needs to characterize the transcriptome of many individual corneal epithelial cells representing progressive stages of vertebrate corneal cell maturation.

The South African clawed frog, Xenopus laevis, has been a valuable research model, particularly for studying eye tissue development, repair and regeneration, which includes the cornea and lens (Barbosa-Sabanero et al., 2012; Henry et al., 2008; Kha et al., 2018; Tseng, 2017). The anatomy and development of the frog cornea are nearly identical to that of humans (Hu et al., 2013) making it an excellent, low-cost vertebrate model to study cornea biology and determine the dynamics of corneal stem cells. Early during development, the larval corneal epithelium consists of a single basal layer, a distinct apical/superficial layer of differentiated cells and relatively few keratocytes underly this epithelium (e.g., stages 48-51) (Nieuwkoop and Faber, 1956). As the larvae undergo metamorphosis and mature into an adult (developmental stage 66), the cornea undergoes dramatic changes-the stromal space thickens and is filled with collagen lamellae and keratocytes, new epithelial layers are added, and limbal crypt-like palisades are observed (similar to those seen in mammals) (Goldberg and Bron, 1982; Hamilton et al., 2016). The presence of basal proliferative stem cells and TACs in the frog cornea has been demonstrated in previous studies. For example, cells undergoing S phase DNA replication and mitosis (examined by EdU labeling and anti-phospho-Histone H3 (S10)) are scattered throughout the basal corneal epithelium of tadpoles (Perry et al., 2013; Thomas and Henry, 2014). Whereas in the adult frog cornea, long-term BrdU, or EdU label-retaining cells, that likely identify CESCs, become concentrated in the limbal area (Hamilton and Henry, 2016). Furthermore, molecular characterization of corneal epithelia of larval and adult frogs, reveals that putative stem cell markers reported in other vertebrates are expressed at different stages in different epithelial layers of the frog cornea (Sonam et al., 2019). Although these markers label different cellular layers and regions of the corneal epithelium during maturation, none was found to be unique to CESCs or TACs. This is in general agreement with the conclusions reached by immunolocalization studies using corneas of other 
vertebrates (Kammergruber et al., 2019; Morita et al., 2015; Mort et al., 2012; Nowell and Radtke, 2017; Schlotzer-Schrehardt and Kruse, 2005). However, these studies provide only a glimpse into the genes expressed by these cells. Single-cell resolution molecular data is needed to provide a comprehensive, unbiased picture of tissue heterogeneity and to better understand the cellular states and transcriptional profiles during corneal differentiation.

Single-cell RNA sequencing (scRNA-seq) has emerged as a revolutionary tool that allows simultaneous, unbiased sampling of individual cells for high-throughput gene expression profile analysis to determine the cellular, as well as molecular heterogeneity in various tissues and organs (Zheng et al., 2017). This nextgeneration sequencing technology has enabled the identification of cell subpopulations, analysis of rare cell types, reconstruction of cell lineage trajectories and the building of gene regulatory networks for tissues and organs including the skin, heart, kidney, uterine epithelium and the intestinal epithelium (Griffiths et al., 2018; Haber et al., 2017; Haensel et al., 2020; Joost et al., 2016; Lescroart et al., 2018; Park et al., 2018; Wu et al., 2017). scRNA-seq has been particularly helpful for gaining insights into the biology and transcriptional states of different types of stem cells, including hematopoietic progenitors, neural progenitors, embryonic stem cells, muscle stem cells and others (Dell'Orso et al., 2019; Klein et al., 2015; Kumar et al., 2017; Llorens-Bobadilla et al., 2015; Zhou et al., 2016). To date, a few studies have used scRNA-seq to gain insights into the molecular and cellular heterogeneity of eye tissues, including human and mouse retina (Macosko et al., 2015; Voigt et al., 2019) and mouse cornea (Kaplan et al., 2019).

Here, we use scRNA-seq to expand our understanding of the vertebrate corneal epithelium in an amphibian model, having undertaken a comprehensive

148 characterization of cellular and transcriptional heterogeneity to identify novel corneal 149 marker genes. By examining 4,810 epithelial cells of tadpole corneas, we identified

150 five distinct cell clusters, each having discrete transcriptional signatures. We used

151 immunofluorescence studies to spatially map the scRNA-seq molecular

152 heterogeneities (for specific genes, such as cldn4, krt8.2) in the intact corneal tissue.

153 In order to better understand the dynamics of corneal cells during maturation, we

154 also reconstructed corneal differentiation by ordering epithelial cells along a pseudo155 temporal trajectory. Furthermore, our analysis of gene regulatory networks helped 156 uncover the dynamic activity of key regulons within the corneal epithelium, that 
control proliferation and differentiation within this tissue. This is the first study to uncover the transcriptional profile of epithelial cells in the larval frog cornea. The Xenopus corneal epithelium is characterized by robust regenerative capacity and is also the source of regenerated lenses (Freeman, 1963; Perry et al., 2013). This work sets the stage for future scRNA-seq research to examine gene expression profiles during various wound repair and regeneration stages, as well as discern the cellular source and precise role of specific genes involved in corneal cell differentiation and lens regeneration.

\section{RESULTS}

\section{Single-cell RNA sequencing identifies the major cell types in the tadpole}

\section{corneal epithelium}

To study the cellular and transcriptional heterogeneity during the early stages of cornea development, we isolated corneal epithelial cells from frog larvae. We developed an Accutase enzyme-based digestion method for dissociating single cells, pooled from 80 larval corneal epithelia (Fig. 1A). Using the 10X Genomics-based scRNA-seq platform, we sequenced 5,173 cells with an average of 83,449 reads per cell and the median number of genes detected per cell was 2,559 (Table S2). For quality control and filtering of reads, a standard computational pipeline in Seurat was used, following which 4,810 high-quality cells were retained and used for downstream computational analysis (Fig. 1B and Fig. S1). Next, an unbiased, graph-based clustering algorithm of the Seurat software was used to group cells according to their gene expression profiles. We identified five distinct cell clusters, visualized in two-dimensional space using Uniform Manifold Approximation and Projection (UMAP) (Becht et al., 2018) (Fig. 1C).

To broadly attribute cell identities to these clusters, expression of known celltype-specific marker genes reported from corneal studies in various vertebrates (Castro-Muñozledo, 2015; Chen et al., 2004; Davies et al., 2009; Yam et al., 2020; Yi et al., 2000) was compared across clusters (Fig. 1D). In addition, the clusters were examined for biomarkers that we previously characterized in larval Xenopus corneas (Sonam et al., 2019) (Fig. 2). Clusters 1 and 2 are comprised of basal epithelial cells. The identity of basal cells was established by the localized expression of tp63.L, tp63.S, krt19.L, krt19.S, pax6.L, itgb1.L and itgb1.S marker genes (Fig. 2A- 
G), which we immunolocalized to the larval corneal basal epithelium in our earlier work. Likewise, other known basal epithelial markers, including txnip.L, fzd7.L, krt15.1.L, krt15.1.S, and krt15.2.L, were also enriched in these two clusters, further confirming their identity (Fig. S2A). Cells in clusters 3 and 4 expressed markers of

194 differentiated epithelial cells (tjp3.L, tjp3.S, ocln.L, ocln.S, gjb1.L and gjb1.S), known

195 to be associated with apical cellular layers (Fig. S2B). Previously, we found beta-

196 catenin as a marker specific for apical epithelial cells in the tadpole cornea (Sonam

197 et al., 2019). However, in the current transcript dataset, the expression of ctnnb.L and ctnnb.S genes was detected in basal cells as well (Fig. $2 \mathrm{H}-\mathrm{I})$. As this observation does not fully agree with our earlier immunolocalization result, the differences could be related to those in protein and transcript expression. We also identified that marker gene e-cadherin (cdh1.S) was expressed in both basal and apical cells (Clusters 1-4; Fig. 2J). This follows our prior observation of E-Cadherin, as a uniform epithelial cell membrane marker in tadpole corneas (Sonam et al., 2019). Markers associated with Cluster 5 cells (vim.L, vim.S, cd34.L, cd34.S and fn1.S) were molecularly very distinct from the other cell clusters and we classified this cluster as corneal keratocytes (Fig. 2K-L and Fig. S2C). The presence of closely associated keratocytes underneath the larval corneal epithelium has been previously demonstrated by immunostaining (Sonam et al., 2019). We did not detect significant expression for known marker genes associated with other ocular cell types, such as zp4, pou6f2, pitx2-markers for corneal endothelial cells (Yoshihara

211 et al., 2017; Yoshihara et al., 2015) and cryaa, cryab-markers for lens cells

212 (Brahma and McDevitt, 1974; Henry et al., 2002), indicating absence of these cell

213 types (Fig. S3A-B). The expression for tcf7/2 - a marker gene that differentiates

214 cornea versus surrounding skin epithelium (Sonam et al., 2019) was observed within

215 very few cells, suggesting possible incorporation of some adjacent skin during

216 corneal surgical isolation (Fig. S3C). On the other hand, no expression of skin

217 melanophore-specific genes (e.g., tyr, $d c t$, sox10, tbx2) was detected (Fig. S4).

\section{Proliferative cells characterize both epithelial layers of the larval cornea} proliferative nature of each cluster (Fig. 3A). We identified that clusters 2 and 3 have a proliferative characteristic, with enriched expression of proliferation marker genes including mki67.L, mki67.S, pcna.L, pcna.L and top2a.L (Fig. 3B-F). In contrast, 
clusters 1, 4 and 5 display a more quiescent nature. To verify the presence of proliferative cells in both epithelial layers, we immunostained the larval cornea using the ubiquitous cell cycle marker PCNA. Using a Xenopus specific antibody (Agathocleous et al., 2009), we detected PCNA labeled nuclei in both basal and apical epithelia (Fig. 3G-H, G'-H'). The presence of proliferative cells in both epithelial layers differs from previous Xenopus corneal studies (Hu et al., 2013; Perry et al., 2013), reporting the presence of dividing cells in the basal epithelium alone. The proliferative cells in the corneal epithelium are those involved in continuous growth and renewal of the tadpole cornea. To support our observation, we immunostained the corneal tissue with an anti-phospho-histone-H3S10 antibody and detected the presence of labeled nuclei in both the epithelial layers (Fig. 3I-J. I'-J'). As phosphorylated Histone H3 is a marker of mitotic cells (Hans and Dimitrov, 2001), the positive staining further reveals cell division activity in this bi-layered epithelium.

\section{Unique marker genes specify cluster identity in an unbiased manner}

In organisms where detailed reference datasets are limited for select tissues and developmental stages, a notable advantage of scRNA-seq analysis is that it enables the identification of new marker genes and regulators of various cell types in an unbiased fashion. Genes with Differential Expression (DE) in a given cluster, when compared to all other clusters (average log fold change $>0.25$; adjusted $p$ value $<0.01$ ), were identified using Seurat's "FindMarkers" function. Furthermore, the lists of DE genes were filtered by applying the criteria that cluster-specific unique marker genes be both highly and uniquely expressed. Therefore, we filtered DE genes using the difference between pct.1 and pct.2, along with a higher overall expression fold change value. For our analysis, we focused on genes expressed in more than $50 \%$ of the cells within that cluster. Fig. 4A depicts the heatmap with an expression profile of the top 10 candidate marker genes for each cluster, with the top 50 candidate marker genes being listed in Table S3. This unbiased approach identified genes with previously established roles in regulating other cell types and processes in Xenopus, as well as other vertebrates. Interestingly, as shown in Fig. 4B, the top-most marker gene in basal cells (Cluster 1 ) and apical cells (Cluster 4 ) is also shared with their proliferative cell clusters, namely clusters 2 and 3 , respectively. 

various collagen transcripts were significantly enriched in these cells, with collagen type XVII alpha 1 (col17a1.L) being the most highly expressed marker gene (Fig. 4B). Collagens are the predominant proteins in the Extra Cellular Matrix (ECM) organization during corneal development and play diverse roles in cell adhesion and differentiation. Our discovery of col17a1 transcripts in basal epithelial cells is particularly interesting. The gene col17a1 encodes a hemidesmosomal transmembrane collagen protein, which is expressed in basal cells of the epidermis. A higher level of col17a1 expression is associated as a marker of long-term epidermal stem cells and is crucial for skin homeostasis (Liu et al., 2019; Matsumura et al., 2016). That basal cells display an increased expression of col17a1.L points towards the possible role of this collagen gene as a unique marker and key regulator of CESCs and TACs present in this epithelial layer.

Looking at the apical corneal cells (Cluster 3 and 4; Fig. 4A), we detected the expression of larval skin-specific genes (e.g., dan4l.L) (Schreiber and Brown, 2003), goblet cell genes (e.g., itln1) (Dubaissi and Papalopulu, 2011), thyroid hormoneregulated genes (e.g., thdl18.S) (Furlow et al., 1997) and genes mediating signal transduction, as well as membrane permeability and stability (e.g., upk1b.L, atp1b2.L) (Eid and Brandli, 2001; Liao et al., 2018). The gene most uniquely enriched in apical cells encodes otogelin-like 2 (otog/2.L; Fig. 4B), a mucin glycoprotein secreted by small secretory cells (SSCs) and goblet cells of the larval epidermis. Otogl2 has been characterized as a major structural component of the mucosal protective barrier in Xenopus (Dubaissi et al., 2018; Dubaissi et al., 2014). Interestingly, in either of the apical epithelial clusters (Clusters 3 and 4 ) we did not detect the presence of genes associated with melanophores (tyr, dct, mitf, sox10) (Kawasaki et al., 2008; Kumasaka et al., 2003) that characterize the pigmented skin epithelium (Fig. S4). The absence of pigmentation is a characteristic feature of the transparent cornea, which otherwise is anatomically continuous with the surrounding skin.

We next focused on the proliferative cell clusters (Cluster 2 and 3 ) to identify their transcriptional heterogeneity. We determined that both these clusters had enriched expression of cell cycle-regulated genes (incenp.L, cenpe.L, smc2.L, cdca3.L; Fig. 4A), indicating that these cells are likely at different stages of cell cycle progression. The gene belonging to the Structural Maintenance of Chromosomes 
(SMC) family, smc4.L was the top marker gene in these cells (Fig. 4B). The SMC family member proteins are known to play crucial roles in mitotic chromosome condensation and segregation (Schmiesing et al., 2000). As one of the subunits of condensin I, SMC4 is widely conserved across eukaryotes and modulates chromosome structure for mitosis (Schmiesing et al., 1998).

For the corneal keratocyte cells (Cluster 5) — the neural crest-derived cells crucial for the formation and maintenance of the corneal stroma - a number of mesenchymal genes, particularly those involved in ECM deposition, cell adhesion and Epithelial to Mesenchymal Transition (EMT) (twist2.S, mfap2.L, mfap2.S, nid1.S, olfm/3.S) were enriched (Fig. 4A). The top-most candidate in this gene list was vimentin (vim.S; Fig. 4B). As mentioned earlier, the presence of vimentin labeled keratocytes underneath the bi-layered epithelium has been described in tadpole corneas (Sonam et al., 2019). Overall, our dataset provides novel insights about a repertoire of genes that likely regulate the formation of corneal epithelial and stromal layers in these amphibians.

As various keratins play an integral role in the formation of the corneal epithelium, we also analyzed the cell-type-specific expression of some of the key keratins uniquely enriched in our dataset. Our results showed that the gene keratin 62 (krt62.L and krt62.S; krt62.L, previously known as xlk) was highly abundant only in the basal corneal cells (Clusters 1 and 2; Fig. 4C). These findings concur with previous reports that this larval-specific keratin is solely expressed in basal cells of

312 tadpole skin and its expression is turned off in the adult (Suzuki et al., 2009;

313 Watanabe et al., 2001). Interestingly, two of the other larval epidermal keratins,

314 namely keratin 12 gene 5 (krt12.5.L and krt12.5.S, also known as $x k 81 b)$ and keratin

31512 gene 4, .L gene (krt12.4.L, also known as $x k 81 a 1)$ were enriched in apical as well

316 as basal corneal cells, but not in corneal keratocytes. However, in the case of

$317 k r t 12.4$, the .S gene had a much-reduced expression in apical and basal cells,

318 suggesting subgenome-specific regulation and expression (Fig. 4D-E). This

319 observation is consistent with earlier studies using in situ hybridization reporting the

320 presence of $x k 81$ genes in the larval tail epidermis (Furlow et al., 1997). 
To validate the spatial expression pattern for some of the newly identified genes, we performed immunohistochemical studies on corneal whole-mounts. This helped us confirm the cellular localization of genes, including claudin 4 (cldn4) and keratin 8 (krt8.2), which we determined as transcriptionally enriched in apical cell clusters (Cluster 3 and 4). Claudins are transmembrane proteins that form tight junctions, and several types of claudins are expressed in the human corneal epithelium. Among these, one of the most consistent and highly-expressed members is Claudin 4 (Ortiz-Melo et al., 2013; Yoshida et al., 2009). A recent study using whole mount preparations of post-metamorphic adult Xenopus corneas reported Cldn4 to be primarily localized to the lateral membranes of the surface corneal epithelium (Wiechmann et al., 2014). However, the authors did not examine Cldn4 expression in the corneal epithelium of younger tadpoles. In our results, we detected widespread Cldn4 immunolabeling in the membrane of the apical epithelial cells (Clusters 3 and 4, Fig. 5A-B,B'). However, the staining was absent in basal corneal cells (Clusters 1 and 2, Fig. 5A,C, C'), which agrees with our transcript dataset.

Another gene enriched in the apical cell clusters (Clusters 3 and 4 ) of the transcript dataset that we successfully validated was the intermediate filament protein, keratin 8.2 (krt8.2.L and krt8.2.S). Different type I and type II keratins are simultaneously expressed in keratinocytes-a major cell type of mammalian epidermis that maintains its barrier function (Ramms et al., 2013). Keratin 8, a marker of simple epithelium, is a prominent basic Type II keratin that is expressed early during epidermal development (Romano et al., 2012). A monoclonal Xenopus specific antibody (Kim et al., 2020; Mariani et al., 2020) was used to examine the corneal expression of this keratin. We observed a mosaic staining pattern, restricted to apical epithelial cells of the larval cornea (Clusters 3 and 4; Fig. 5D-E,E'). The expression was primarily cytoplasmic with some apical cells showing relatively higher expression than adjoining cells. The Krt8.2 staining pattern in apical cells may indicate that these cells are at different stages of cellular differentiation, as the cornea matures. On the other hand, no expression was detected in basal epithelial cells (Fig. 5D,F,F'). As reported in studies on mice epidermis formation (Romano et al., 2012), it is likely that the high nuclear expression of transcription factor p63 in basal cells (Sonam et al., 2019) is associated with suppressed expression of Keratin 8 in those cells. 
Analysis of gene expression trajectories reveals the differentiation pathway of corneal epithelial cells

As the vertebrate corneal epithelium is a self-renewing tissue (Kruse, 1994), it contains cells at different stages of differentiation (Beebe and Masters, 1996; Tseng, 1989). Therefore, to derive the differentiation trajectories of corneal epithelial cells, we leveraged one of the most powerful features of scRNA-seq datasets-single cells can be ordered in an unbiased way along a path to resolve their developmental progressions. We performed pseudo-time-based ordering of single cells from clusters 1, 2, 3 and 4 using Monocle's network-based approach (Trapnell et al., 2014). The corneal keratocytes cluster (Cluster 5) was omitted from this analysis, as it was transcriptionally disconnected from the other four cell types (i.e., mesenchymal in origin). We found that the pseudo-time path has two branches (Fig. 6A), and different cell clusters can be arranged relatively clearly at different branch arms of this path. This pseudo-temporal ordering of cells along the axis originating from basal cells towards the terminally differentiated apical state was in agreement with the known corneal stratification in tadpoles (Hu et al., 2013). In principle, the distribution characteristics of different cell types on the differentiation trajectory can preliminarily describe the relationships between these cells during the development period. The distribution of basal cells (Cluster 1 ) and basal proliferative cells (Cluster 2) in the developmental trajectory is concentrated at the beginning (Fig. 6B), suggesting that their developmental relationships are close. Likewise, the apical epithelial cells (Cluster 4), along with the apical proliferative cells (Cluster 3 ) occupied a position around the second branch point, mostly towards the end of this path (Fig. 6B).

Next, we identified the expression dynamics of the top 2000 genes that change as a function of progress through pseudo-time. These genes can be categorized into four distinct gene classes (namely Class A, B, C and D; Fig. 6C). To better understand the biological significance of these classes, we performed Gene Ontology (GO) analysis (see Material and Method). Genes predominantly expressed at the beginning of the developmental trajectory show an abundance of GO terms associated with cell proliferation, cell adhesion, integrin-mediated signaling, Wnt signaling, ECM organization and EMT (Classes B and D). At the other end of the trajectory, genes whose expression peaks late along this trajectory are enriched in GO terms associated with keratinocyte differentiation, the establishment of skin 
barrier functions and NF-kappaB signaling (Class A). In addition, the smallest class (Class $\mathrm{C}$ ) with genes that peak transiently along the pseudo-time was enriched for ribosomal biogenesis and protein-membrane targeting genes (Table S4).

In addition to getting a coarse idea of broad GO terms that vary through corneal cell maturation, the pseudo-time trajectory can be used to gain insight into the temporal expression changes of individual genes. This provides us with a refined view of the changes that corneal epithelial cells undergo during their transition from basal to terminally differentiated apical states. As signaling mechanisms (such as Retinoic Acid, FGF and Wnt/ $\beta$-catenin), processes of ECM deposition and EMTrelated processes are crucial for corneal formation and differentiation (Dhouailly et al., 2014; Nakatsu et al., 2011), we closely investigated the expression changes of genes implicated in these pathways/processes along the pseudo-time (Fig. 6D). Retinoic acid signaling genes (cyb26b1.S, aldh1a1.L, aldh1a1.S) show an increasing trend along this pseudo-time, while genes in the FGF (fgfbp2.L, fgfbp2.S, fgfr2.L, fgfr2.S) and Wnt/3-catenin (wnt3a.L, wnt3a.S, wnt4.S, wnt7b.L, wnt7c.L, wnt9a.S) pathways show a reduction in expression. We also noted a dramatic reduction in expression of genes that primarily constitute the corneal ECM (Ium.L, lum.S, sparc.L, sparc.S, col12a1.L, col12a1.S, itga6.L, itga6.S, col6a2.L, col6a2.S) along the progression of pseudo-time. A similar trend in reduction of expression was observed for EMT-related genes (pcdh7.S, snai1.S). On the other hand, genes characteristic of Xenopus skin formation (otogl2.L, muc2, itln1.S and znf750.L) gradually increase.

Furthermore, we noted a remarkable increase in expression levels of thyroid hormone-controlled genes (thdl18.S, thdI20.S and thdl17.L) along the pseudo-time axis. Changes in thyroid hormone gene expression dynamics in frog cornea represents a novel observation and has not been characterized in earlier studies focused on Xenopus eye development. These changes are similar to those observed in frog skin (Suzuki et al., 2009; Yoshizato, 2007) and the corneal epithelium in these anurans likely also undergoes thyroid hormone-mediated remodeling-a hallmark characteristic of metamorphosis.

\section{Distinct gene regulatory networks are active during corneal differentiation} In order to characterize gene regulatory networks (GRNs) that govern corneal development and differentiation, we used the SCENIC pipeline to create a gene 
regulatory framework (Aibar et al., 2017). As transcription factors (TFs) are known to be highly conserved despite the allotetraploidization event in Xenopus laevis (Watanabe et al., 2017), we converted the $X$. laevis gene names to their human orthologs (see Materials and Methods). SCENIC calculates the activity of TFs from individual cells by integrating co-expression data with transcription factor motif enrichment analysis, to generate a "regulon." A regulon is comprised of an expressed transcription factor and all of its co-expressed target genes. We determined the regulon activities using Area Under Cell (AUCell), which ranks targets of an individual regulon among the expressed genes, thereby generating a regulon-by-cell activity matrix.

To test our hypothesis that different developmental GRNs might drive cellular transitions during corneal differentiation, we analyzed the AUCell score activity matrix of individual corneal cells in our scRNA-seq dataset. Upon visualization of cell clustering from UMAP-built from the AUCell scores-we observed that corneal cells of a specific type grouped together, highlighting a high degree of similarity in their regulon activity (Fig. 7A). Importantly, the basal epithelial cells, including the proliferative population, formed distinct and non-overlapping clusters, which represent their discrete GRNs. Likewise, the proliferative cells of the apical epithelia clustered adjacent to apical cells and away from the basal population, demonstrating that two distinct regulons are active in the superficial corneal layer. The corneal keratocytes clustered distinctly away from both basal and apical cells, which indicates that regulatory networks driving these cells are strikingly different.

In addition, we explored the regulons that are most upregulated in each of the cell clusters to identify the main TFs and their target genes that drive those cell states (Fig. 7B). In line with previous reports, in the outermost (apical) epithelial cells, we found increased expression of NF-kB, IRF7 and the ARNTL2 family of transcription factors that play essential roles in corneal wound healing, suppressing corneal infections and regulating corneal homeostasis (Alexander et al., 2006; Norman et al., 2004; Swamynathan, 2013). On the other hand, TP73, ASCL2, NFATC1, FOXP2 and SNAI1 regulons were active in basal cells and the basal proliferative cluster but were muted in apical clusters. As proteins of TF families such as the Forkhead box (e.g., FOXP2), basic helix-loop-helix (e.g., ASCL2) and Nuclear Factor of Activated T Cells (e.g., NFATC1) play a key role in maintaining a quiescent and undifferentiated state of stem cells (Keyes et al., 2013; Lay et al., 2016; 
Moriyama et al., 2008), these results support our previous hypothesis (Perry et al., 2013) that corneal stem cells reside throughout the basal epithelium in larvae. As expected, regulons associated with cell proliferation and progenitor maintenance such as E2Fs (E2F3,4,7,8) and EZH2 (Ezhkova et al., 2009; Francesconi et al., 2000) were enriched in the clusters of cycling cells. Regulons such as ELK3 (belonging to the ETS family), KLF7 (of the Kruppel-like Transcription factor family), PAX7 (of the Paired Domain-Homeodomain Transcription factor family) were highly active in corneal keratocytes, but had lowered expression in basal and apical epithelial cell clusters. Previous studies have described the role of these TF families in regulating cell differentiation, cell migration, and matrix formation processes during corneal development (Klein et al., 2017; Yoshida et al., 2000).

\section{DISCUSSION}

Here, we have used single-cell transcriptional profiling to probe cellular heterogeneity in corneal epithelial tissue of Xenopus larvae. Although the study captures a narrow time-point of larval corneal development, it enabled us to generate a high-resolution atlas that describes the major cell types and reconstructs developmental trajectories of corneal cells under homeostatic conditions. A comprehensive characterization of cell-type-specific marker genes along with an understanding of the corneal epithelial developmental lineage and dynamic regulatory network of key transcription factors will provide future avenues to optimize the maintenance and differentiation of corneal cells in the frog and other vertebrates.

The larval cornea comprises five discrete cell types, including proliferative cells in both apical and basal layers

The formation of the Xenopus larval epidermis has been extensively characterized in several studies and remains of critical biomedical interest (Boon et al., 2014; Walentek and Quigley, 2017). Nevertheless, despite sharing a high degree of developmental and anatomical similarity to human corneas (Hu et al., 2013), the gene expression profile of frog corneal development has not been previously characterized. Our study profiled nearly five thousand corneal cells, and this data offers valuable insights into cellular processes that characterize distinct corneal cell types-basal cells (Cluster 1), apical cells (Cluster 4), corneal keratocytes (Cluster 5) and proliferative cells of basal and apical epithelia (Clusters 2 and 3, respectively). 
The identification of proliferative cells contained in both the epithelial layers was intriguing (Fig. 3), as past studies have postulated that proliferative cells exist mainly within the basal epithelial layer and upon differentiation, these cells populate the outermost layer of the corneal epithelium (Li et al., 2017; Perry et al., 2013; Sun and Lavker, 2004; Yoon et al., 2014).

Using an unbiased approach to marker gene calling, we identified expression features that define each cluster and determined unique genes that characterize and regulate these cell states (Fig. 4). Examination of specific corneal layers revealed that the outer (apical) layer of corneal epithelium expresses genes associated with specialized epidermal cell types (goblet cells, ionocytes, small secretory cells) but lacks pigmented melanophore genes. The absence of pigmentation is expected in the cornea, as maintaining optical clarity is essential for proper vision. The inner (basal) epithelial layer is characterized by an abundance of ECM genes, including various collagens, integrins, and keratins. Some of the newly identified basal marker genes (e.g., col17a1, col5a3, cldn1, krt62 and smc4) may contribute as regulators of corneal epithelial development and differentiation, particularly of CESCs and early TACs, in this amphibian and other vertebrates.

\section{Identification of dual populations of quiescent and proliferative cells}

Analyses of the data reveal two distinct populations of proliferative cells: one that is closely related to those of the quiescent basal cell cluster and another that is closely associated with cells of the quiescent apical cell cluster. The basal proliferative cells (Cluster 2) showed an abundance of basal cell markers, also expressed in the non-proliferative basal cells of Cluster 1 (e.g., col17a1.L, krt19.L). In contrast, the apical proliferative cells (Cluster 3 ) expressed differentiated apical cell markers found in the non-proliferative apical cells of Cluster 4 (e.g., cldn4.L, otogl2.L) (see Fig. 4 and Table S3).

Previous studies considered genes such as Mki67 and PCNA to represent potential markers for proliferative TACs (Guzman et al., 2013; Lehrer et al., 1998). In fact, both proliferative cell clusters (Clusters 2 and 3) exhibited an enriched expression of these proliferation marker genes. These populations of basal and apical proliferative cells, respectively, could represent the so-called "early TACs" and

524 "late/mature TACs" proposed in a recent scRNA-seq study of the mice corneal epithelium (Kaplan et al., 2019). However, we could not compare the entire corneal 
epithelial gene expression profile of mouse to that of tadpoles, due to unavailability of raw data for the mice study.

Based on the larval corneal expression profiles, it is still a challenge to discern stem cells from early stage TACs - a conclusion in line with other studies focused on identifying specific markers for CESCs and TACs (Lavker et al., 2020; Mort et al., 2012). In fact, it is possible that the two basal corneal epithelial cell populations (Clusters 1 and 2) represent only one cell type, and our analysis has simply captured those cells when they are also expressing genes that regulate mitosis.

While we did not identify a smaller discrete population of CESCs, we did observe a higher level of expression of epithelial stem-cell related marker genes (e.g., tp63, krt19, krt15.2, cldn1, itga6, itgb4, col17a1) in cells of both basal clusters (Clusters 1 and 2). The similar transcriptional profiles of these clusters suggest that the entire basal cell population behaves like stem cells in Xenopus larvae. This observation supports an earlier proposal that oligopotent stem cells may be distributed throughout the basal corneal epithelium during larval stages (Perry et al., 2013). In future studies, it will be important to examine the adult frog cornea, where evidence suggests that EdU label-retaining putative CESCs represent a relatively smaller population of cells that reside in the limbus (Hamilton and Henry, 2016). The altered spatial distribution of cells in the mature cornea may affect gene expression dynamics, and perhaps one will be able to better distinguish CESCs and TACs.

It is also of some significance that we did not find evidence for a more gradual transition in gene expression, as the corneal epithelial cells undergo differentiation (and a greater number of transitional cell types/clusters). Instead, our observations suggest a model in which a more discrete genetic switch occurs as cells transition from basal to apical fates.

Variable developmental trajectories and discrete TF regulatory networks govern the process of corneal maturation

To dissect the temporal and spatial distribution of corneal cells, we performed a pseudo-time analysis of our scRNA-seq data (Fig. 6). As illustrated by the waves of gene expression identified here, cells transitioning from basal to apical layers follow finely resolved developmental trajectories. Our study offers the required resolution to distinguish the stepwise temporal progressions connecting the beginning and end of corneal epithelial differentiation. Although it cannot be ruled out 
560 that the progressions that individual cells undergo during differentiation may be more

561 dynamic than captured in this analysis, this data definitely adds to our current understanding of corneal development and differentiation. We are particularly intrigued by our novel finding of the role of thyroid hormone genes in corneal differentiation, and seek to explore this in future studies. Furthermore, a number of signaling pathways appear to be involved (e.g., Retinoic Acid, FGF, Wnt/ $\beta$-catenin, BMP) that have also been shown to play crucial roles in supporting cornea-lens regeneration in frogs (Day and Beck, 2011; Fukui and Henry, 2011; Hamilton et al., 2016; Thomas and Henry, 2014). In the future, it will be interesting to examine the gene expression profiles and developmental trajectory of regenerating individual corneal cells across various stages of lens reformation and discern their spatiotemporal progressions.

At the transcriptomic level, the expression patterns of many key genes involved in corneal epithelial development are known, but regulators of these genes are still being identified (Stephens et al., 2013; Swamynathan, 2013). Here, we leveraged our scRNA-seq data to computationally infer dynamic TF networks controlling corneal cell states, as well as its maturation process. Distinct groups of TFs characterize cell fate changes during the progression from the undifferentiated basal to the differentiated apical states (Fig. 7). Many of these newly identified TFs and their target genes (e.g., FOX and bHLH for basal cells and NF-kB and IRF for apical cells) can be explored further as key regulators of corneal epithelium formation and maintenance, including that of CESCs and TACs in vertebrates.

\section{Future scRNA-seq to elucidate cornea-lens regeneration in frogs}

Despite sharing an extensive parallel with skin epithelium both in terms of cell types and transcriptional profile, the corneal epithelium in these anurans is unique. Only the tadpole cornea and pericorneal epithelium (lentogenic area-a combined region extending twice the diameter of the eye) is capable of regenerating a functional lens. On the other hand, the flank epidermis (outside this lentogenic area) does not possess this competence (Cannata et al., 2003; Freeman, 1963). Earlier work on Xenopus lens regeneration had identified some candidate genes, including pax6 and fgfr2 (bek isoform), that may contribute to the cornea's capacity to regrow

592 a lens (Arresta et al., 2005; Gargioli et al., 2008). Future scRNA-seq studies of 
593 tadpole flank epidermis will enable us to compare the molecular heterogeneity of

594 both these epithelia, to identify the entire gene repertoire that contributes to the cornea's capacity to regenerate a lens. Likewise, it will be valuable to examine the corneal epithelium of metamorphosed frogs to understand what transcriptional changes lead to its lost lens regenerative capacity (Filoni et al., 1997; Hamilton and Henry, 2016).

\section{Xenopus laevis as a corneal disease model}

Xenopus laevis is a well-established model for studying eye development and regeneration processes (Henry et al., 2008). These frogs share a high degree of synteny with humans, with around $80 \%$ of human disease genes having orthologs in these amphibians-making them an excellent choice to model human diseases (Blum and Ott, 2018; Nenni et al., 2019). Recently, robust Xenopus ocular disease models have been established for congenital eye malformations including aniridia, cataract, megalocornea, microphthalmia, coloboma and corneal stem cell deficiency (Adil et al., 2019; Nakayama et al., 2015; Pfirmann et al., 2015; Viet et al., 2020). Along with being easily accessible for experimental manipulation and imaging, the frog cornea resembles that of humans (Hu et al., 2013) that makes it a suitable vertebrate model for human corneal disease-related investigations. In our current study, several genes associated with human corneal dystrophies were found to be expressed in the tadpole cornea (e.g., LUM, SLC4A11, SOD1 and KERA; see Fig. S5)(Klintworth, 2009). For instance, the putative Xenopus ortholog of the KERATIN 12 (KRT12) gene related to Meesmann's corneal dystrophy (Irvine et al., 2002; Irvine et al., 1997) was expressed significantly in cells of the apical and basal epithelium (i.e., krt12.5.L, krt12.5.S, krt12.4.L; Fig. 4D-E). With the advanced genetic manipulation tools now available for Xenopus (Tandon et al., 2017), frogs can be developed to model human corneal dystrophies and to better understand disease pathobiology.

\section{Conclusion}

In summary, the transcriptional atlas of the Xenopus cornea described here provides a unique spatiotemporal perspective of corneal epithelium differentiation. One can extrapolate the findings of this study to test a number of newly identified enriched basal corneal epithelial genes for their potential application as specific 
markers in other vertebrates, including mice and humans. This also indicates that scRNA-seq can be used as a sensitive approach to comprehensively document transcriptional profiles at various stages of mammalian corneal development to reconstruct precise developmental lineages of corneal cells. An extensive molecular and cellular characterization of corneal epithelia among various vertebrates will ultimately aid in determining accurate biomarkers for the identification and isolation of stem cells for clinical purposes. This will also be crucial for designing and improving therapeutic treatments for diseases and dystrophies that affect corneal epithelial integrity.

636

\section{MATERIALS AND METHODS}

Animals

Adult Xenopus laevis were obtained from Nasco (Fort Atkinson, WI). Fertilized eggs were collected, and larvae were raised to Stage 49-51 based on developmental staging by Nieuwkoop and Faber (1956). All animal care and experiments performed in this study were approved and monitored by the Institutional Animal Care and Use

643 Committee (IACUC) and the Division of Animal Resources (DAR) at the University of 644 Illinois.

\section{Single-cell dissociation}

Tadpoles were anesthetized at room temperature by incubation for 30-60 seconds in a 1:2000 dilution of MS222 (ethyl 3-aminobenzoate methanesulfonate, Sigma, St. Louis, MO) diluted in 1/20X Normal Amphibian Media, NAM (Slack, 1984). Anesthetized tadpoles were transferred to clay-lined dishes containing $\mathrm{Ca}^{++}-$ $\mathrm{Mg}^{++}$free Dulbecco's Phosphate Buffered Saline (1X DPBS; Corning, NY, \#21-031$\mathrm{CV}$ ). The corneal epithelial tissue was dissected using fine microscissors (Henry et al., 2018), taking care not to include any surrounding skin. The skin is demarked by the outer edge of the orbit, a lack of transparency, and the obvious presence of pigmented melanophores. To limit the amount of time needed to collect these tissues, three operators simultaneously collected a total of approximately 80 corneas in three separate glass depression dishes containing $400 \mu$ IX DPBS, on ice. Care was taken to ensure that corneas were carefully removed from the tip of the forceps 
660

661

662

663

664

665

666

667

668

669

670

671

672

673

674

675

676

677

678

679

680

681

682

683

684

685

686

687

688

689

690

691

692

tip, most of the DPBS was gently removed without disturbing the corneas at the bottom of each glass dish. To dissociate the corneal epithelial tissue, $\sim 350 \mu$ of Accutase (CellnTec Advanced Cell Systems, Bern, Switzerland) was added to each dish, and the dishes were covered with plastic petri dish lids $(35 \times 10 \mathrm{~mm}$, Corning, \#351008) flat side down, and wrapped tightly with lab tape to secure them and prevent desiccation. Next, the dishes were incubated at $37^{\circ} \mathrm{C}$ for 35 minutes with intermittent trituration using a $200 \mu \mathrm{l}$ pipette tip. To stop the reaction, $200 \mu \mathrm{l}$ of media containing 61\% L-15 (Invitrogen, Carlsbad, CA), $0.5 \mu \mathrm{M}$ EDTA (Invitrogen) and 10\% Fetal Bovine Serum (Invitrogen) was added to each dish. For mechanical dissociation, the suspension was finally triturated 8-10 times using the $200 \mu$ pipette tip. The three cell suspensions were pooled in a $2 \mathrm{ml}$ LoBind microcentrifuge tube (Eppendorf, Enfield, CT; \#022431048), spun at $325 \mathrm{~g}$ for 5 minutes in a fixed angle centrifuge, and resuspended in $200 \mu \mathrm{L}-15$ with $10 \%$ FBS and $0.5 \mu \mathrm{M}$ EDTA. Finally, the cells were passed through a $40 \mu \mathrm{m}$ FlowMi cell strainer (Bel-Art, Wayne, NJ; \#136800045) and collected in a 2ml LoBind tube. Cell viability was assessed using Acridine Orange/Propidium lodide (AO/PI) staining solution (Nexcelom Bioscience, Lawrence, MA, \#CS2-0106) that labels live and dead cells respectively, and counted using an automated cell counter (Cellometer K2, Nexcelom Bioscience).

\section{Library preparation and sequencing}

The single-cell RNA-seq library was generated using the 10X Genomics Chromium Single Cell 3' Kit v3 (10X Genomics, San Francisco, CA) and sequenced with Illumina NovaSeq 6000 on a SP flow cell to obtain 150bp paired reads. Library preparation and sequencing was conducted at the High-Throughput Sequencing and Genotyping Unit of the Roy J. Carver Biotechnology Center at the University of Illinois.

\section{scRNA-seq data processing}

RNA sequencing reads for the $10 \mathrm{X}$ library were processed using the CellRanger v3.1.0 pipeline by 10X Genomics. For generating the CellRanger reference, the Xenopus laevis v9.2 reference genome and gene models were downloaded from Xenbase

(http://ftp.xenbase.org/pub/Genomics/JGI/Xenla9.2/XENLA 9.2 Xenbase.gff3) 
693 (Karimi et al., 2018). Further downstream processing was performed in R Studio

694 v3.6.1. The output from CellRanger was uploaded into an R Studio session, and

695 processed using the Seurat v3.1 pipeline (Butler et al., 2018; Satija et al., 2015),

696 wherein a standard filtering and preprocessing pipeline was employed. Genes

697 expressed in less than 3 cells, and cells expressing $<200$ or $>3000$ genes were

698 removed from downstream analysis. We used a $5 \%$ cutoff for mitochondrial reads to

699 remove dead/apoptotic cells. Post-normalization, we scaled data using the

700 ScaleData function and performed this for all features/genes. We used

701 FindNeighbours and FindClusters functions at parameter values of dims 1:20 and

702 resolution 0.1 , respectively. Significantly enriched genes within clusters were

703 identified using the FindMarkers function, with a min.pct parameter of 0.25. Cell type

704 identities were assigned using expression patterns of previously established marker

705 genes from the available literature (Castro-Muñozledo, 2015; Guo et al., 2018; Li et

706 al., 2017) and our previous study (Sonam et al., 2019). The frog X. laevis is

707 allotetraploid, and gene expression data can be accessed for each allele from both

708 the Large (Gene.L) and/or Short (Gene.S) chromosomes (Session et al., 2016).

709 Taking into consideration that these alleles may have different functions, we reported

710 cluster-specific allele expression patterns for each gene.

\section{Trajectory Analysis}

713 To infer the trajectory of single cells, we used Monocle v2.0 (Trapnell et al.,

714 2014) and applied the DDRtree algorithm for dimensionality reduction. Differentially

715 expressed genes were calculated using comparison across the different clusters

716 found by Seurat v3.1 above. We used the Top 3000 genes to order cells and

717 determine the pseudo-time trajectory. Relevant functions within Monocle2 were used

718 to plot a heatmap for genes varying along the pseudo timeline. To define the Gene

719 Ontology (GO) for the regulated genes along the trajectory, we humanized the $X$.

720 laevis gene names and converted them to human Ensembl GenelDs, and used

721 DAVID 6.8 for the GO analysis (Dennis et al., 2003). GO option GOTERM_BP_ALL

722 was selected, and the terms with a p-value $<0.05$ were chosen as significant

723 categories. 
For cell cycle analysis, we used a previously defined core set of $84 \mathrm{G} 1 / \mathrm{S}$ and 98 G2/M cell cycle genes (Aztekin et al., 2019). We identified the approximate cell cycle state of each cell with the average expression (called the "cycle score") for the two gene sets using the Cell cycle scoring function in Seurat v3.1. If the cycle scores of $\mathrm{G} 1 / \mathrm{S}$ and $\mathrm{G} 2 / \mathrm{M}$ were both less than 2, the corresponding cell was considered to be quiescent; otherwise, the corresponding cell was identified as being proliferative.

\section{Gene Regulatory Network (GRN) analysis}

We used the single-cell regulatory network inference and clustering (SCENIC) pipeline (Aibar et al., 2017) to estimate the AUCell Score activity matrix from the scRNA-seq dataset (Chembazhi et al., 2020). Briefly, since current relevant databases don't hold gene regulatory information specific to $X$. laevis, we decided to collapse raw counts from .L and.$S$ gene forms in our data. This collapsed data was then processed in the Seurat v3.1 pipeline, as explained above. A normalized count table was extracted from the Seurat object, and Xenopus genes with a known human ortholog were retained for downstream analysis, and the gene names were humanized. Unlike the standard SCENIC workflow where this AUCell score activity matrix is binarized by thresholding to generate binary regulon-activity matrix, we retained the full AUCell score for all further analysis. The matrix of AUCell score containing regulons (rows) $x$ cells (columns) was used as input to Seurat object and used to cluster and identify important regulons for each previously identified cluster.

\section{Immunofluorescence staining and imaging}

Immunostaining of larval corneas was performed using a previously published protocol (Sonam et al., 2019). Briefly, the larval specimens were fixed in Dent's fixative (80\% methanol, $20 \%$ dimethyl sulfoxide, DMSO), or 3.7\% ParaFormaldehyde (PFA) fixative. Next, the eyes were excised from each sample, taking care to keep the cornea intact. The excised eyes were washed six times for 10 minutes each in 1X PBST (Phosphate buffered saline; $1.86 \mathrm{mM} \mathrm{NaH}_{2} \mathrm{PO}_{4}, 8.41 \mathrm{mM} \mathrm{Na}_{2} \mathrm{HPO}_{4}, 175$ $\mathrm{mM} \mathrm{NaCl}, \mathrm{pH} 7.4$, containing 0.5\% Tween-20). Blocking was done using $5 \%$ Bovine Serum Albumin/10\% normal goat serum/1X PBST for 2 hours at room temperature. 
washes were done with 1X PBST prior to incubating the eyes with secondary antibodies. Goat anti-mouse Alexa-Fluor 488 or 546, and goat anti-rabbit Alexa-Fluor 488 or 546 (Invitrogen, Rockford, IL) were used as secondary antibodies at a concentration of 1:300 diluted in blocking solution for 2 hours at room temperature. Finally, the eyes were washed twice with 1X PBST and incubated with $1 \mu \mathrm{g} / \mathrm{ml}$ solution of Hoechst 33342 (Molecular Probes, Eugene, OR) in 1X PBS for nuclear counter-staining. RainX (ITW Global Brands, Houston, TX) treated slides were used for mounting the corneas, and SlowFade antifade reagent (Life Technologies,

Eugene, OR) was used for the mounting media. To flat mount the cornea on a slide, labeled corneas were carefully removed from the whole eyes, and small, peripheral, radial incisions were made to facilitate flattening during the mounting process. Confocal imaging of immunolabeled larval corneas was performed using an inverted LSM 700 microscope (Carl Zeiss, Munich, Germany). The Z-stacks were processed with Zen software (Carl Zeiss, Munich, Germany). The images were compiled using Adobe Photoshop.

\section{ACKNOWLEDGEMENTS}

We acknowledge support from the High-throughput sequencing center, UIUC and the Developmental Studies Hybridoma Bank for $1 \mathrm{H} 5$ antibody.

\section{COMPETING INTERESTS}

The authors have no competing interests to disclose.

\section{FUNDING}

783 Work in Henry lab was supported by funds from the National Institute of Health grant 784 EY023979. Work in Kalsotra lab is supported by (R01HL126845, R01AA010154).

785 S.B is supported by the NIH Tissue microenvironment training program (T32EB019944), and the Scott Dissertation Completion Fellowship.

\section{DATA AVAILABILITY}

789 All raw RNA-seq data files are available for download from the NCBI Gene

790 Expression Omnibus (http://www.ncbi.nlm.nih.gov/geo/) under accession number 791 GSE154896. 


\section{REFERENCES}

793

794

795

796

797

798

799

800

801

802

803

804

805

806

807

808

809

810

811

812

813

814

815

816

817

818

819

820

821

822

823

824

825

826

827

828

829

830

831

832

833

834

835

836

837

838

839

Adil, M. T., Simons, C. M., Sonam, S. and Henry, J. J. (2019). Understanding cornea homeostasis and wound healing using a novel model of stem cell deficiency in Xenopus. Exp Eye Res 187, 107767.

Agathocleous, M., Iordanova, I., Willardsen, M. I., Xue, X. Y., Vetter, M. L., Harris, W. A. and Moore, K. B. (2009). A directional Wnt/beta-catenin-Sox2proneural pathway regulates the transition from proliferation to differentiation in the Xenopus retina. Development 136, 3289-3299.

Aibar, S., Gonzalez-Blas, C. B., Moerman, T., Huynh-Thu, V. A., Imrichova, H., Hulselmans, G., Rambow, F., Marine, J. C., Geurts, P., Aerts, J., et al. (2017). SCENIC: single-cell regulatory network inference and clustering. Nature methods 14, 1083-1086.

Alexander, G., Carlsen, H. and Blomhoff, R. (2006). Corneal NF-kappaB activity is necessary for the retention of transparency in the cornea of UV-B-exposed transgenic reporter mice. Exp Eye Res 82, 700-709.

Amitai-Lange, A., Altshuler, A., Bubley, J., Dbayat, N., Tiosano, B. and ShalomFeuerstein, R. (2015). Lineage tracing of stem and progenitor cells of the murine corneal epithelium. Stem Cells 33, 230-239.

Arresta, E., Bernardini, S., Gargioli, C., Filoni, S. and Cannata, S. M. (2005). Lens-forming competence in the epidermis of Xenopus laevis during development. J Exp Zool A Comp Exp Biol 303, 1-12.

Aztekin, C., Hiscock, T. W., Marioni, J. C., Gurdon, J. B., Simons, B. D. and Jullien, J. (2019). Identification of a regeneration-organizing cell in the Xenopus tail. Science 364, 653-658.

Barbosa-Sabanero, K., Hoffmann, A., Judge, C., Lightcap, N., Tsonis, P. A. and Del Rio-Tsonis, K. (2012). Lens and retina regeneration: new perspectives from model organisms. Biochem J 447, 321-334.

Bath, C., Muttuvelu, D., Emmersen, J., Vorum, H., Hjortdal, J. and Zachar, V. (2013). Transcriptional dissection of human limbal niche compartments by massive parallel sequencing. PLoS One 8, e64244.

Becht, E., Mclnnes, L., Healy, J., Dutertre, C. A., Kwok, I. W. H., Ng, L. G., Ginhoux, F. and Newell, E. W. (2018). Dimensionality reduction for visualizing single-cell data using UMAP. Nat Biotechnol.

Beebe, D. C. and Masters, B. R. (1996). Cell lineage and the differentiation of corneal epithelial cells. Investigative Ophthalmology \& Visual Science 37, 1815-1825.

Blum, M. and Ott, T. (2018). Xenopus: An Undervalued Model Organism to Study and Model Human Genetic Disease. Cells Tissues Organs, 1-11.

Boon, M., Wallmeier, J., Ma, L., Loges, N. T., Jaspers, M., Olbrich, H., Dougherty, G. W., Raidt, J., Werner, C., Amirav, I., et al. (2014). MCIDAS mutations result in a mucociliary clearance disorder with reduced generation of multiple motile cilia. Nature communications 5, 4418.

Brahma, S. K. and McDevitt, D. S. (1974). Ontogeny and localization of the lens crystallins in Xenopus laevis lens regeneration. J Embryol Exp Morphol 32 , 783-794.

Butler, A., Hoffman, P., Smibert, P., Papalexi, E. and Satija, R. (2018). Integrating single-cell transcriptomic data across different conditions, technologies, and species. Nat Biotechnol 36, 411-420. 
Cannata, S. M., Arresta, E., Bernardini, S., Gargioli, C. and Filoni, S. (2003). Tissue interactions and lens-forming competence in the outer cornea of larval Xenopus laevis. J Exp Zool A Comp Exp Biol 299, 161-171.

Castro-Muñozledo, F. (2015). The Mammalian Limbal Stem Cell Niche: A Complex Interaction Between Cells, Growth Factors and Extracellular Matrix. 23-56.

Chang, C. Y., Green, C. R., McGhee, C. N. and Sherwin, T. (2008). Acute wound healing in the human central corneal epithelium appears to be independent of limbal stem cell influence. Invest Ophthalmol Vis Sci 49, 5279-5286.

Chembazhi, U. V., Bangru, S., Hernaez, M. and Kalsotra, A. (2020). Cellular plasticity balances the metabolic and proliferation dynamics of a regenerating liver. bioRxiv.

Chen, Z., de Paiva, C. S., Luo, L., Kretzer, F. L., Pflugfelder, S. C. and Li, D. Q. (2004). Characterization of putative stem cell phenotype in human limbal epithelia. Stem Cells 22, 355-366.

Cotsarelis, G., Cheng, S. Z., Dong, G., Sun, T. T. and Lavker, R. M. (1989). Existence of slow-cycling limbal epithelial basal cells that can be preferentially stimulated to proliferate: implications on epithelial stem cells. Cell 57, 201209.

Davanger, M. and Evensen, A. (1971). Role of the pericorneal papillary structure in renewal of corneal epithelium. Nature 229, 560-561.

Davies, S. B., Chui, J., Madigan, M. C., Provis, J. M., Wakefield, D. and Di Girolamo, N. (2009). Stem cell activity in the developing human cornea. Stem Cells 27, 2781-2792.

Day, R. C. and Beck, C. W. (2011). Transdifferentiation from cornea to lens in Xenopus laevis depends on BMP signalling and involves upregulation of Wnt signalling. BMC developmental biology 11, 54.

Dell'Orso, S., Juan, A. H., Ko, K. D., Naz, F., Perovanovic, J., Gutierrez-Cruz, G., Feng, X. and Sartorelli, V. (2019). Single cell analysis of adult mouse skeletal muscle stem cells in homeostatic and regenerative conditions. Development 146.

Dennis, G., Jr., Sherman, B. T., Hosack, D. A., Yang, J., Gao, W., Lane, H. C. and Lempicki, R. A. (2003). DAVID: Database for Annotation, Visualization, and Integrated Discovery. Genome Biol 4, P3.

Dhouailly, D., Pearton, D. J. and Michon, F. (2014). The vertebrate corneal epithelium: from early specification to constant renewal. Dev Dyn 243, 12261241.

Di Girolamo, N. (2011). Stem cells of the human cornea. Br Med Bull 100, 191-207.

Dubaissi, E. and Papalopulu, N. (2011). Embryonic frog epidermis: a model for the study of cell-cell interactions in the development of mucociliary disease. Disease models \& mechanisms 4, 179-192.

Dubaissi, E., Rousseau, K., Hughes, G. W., Ridley, C., Grencis, R. K., Roberts, I. S. and Thornton, D. J. (2018). Functional characterization of the mucus barrier on the Xenopus tropicalis skin surface. Proc Natl Acad Sci U S A 115, 726-731.

Dubaissi, E., Rousseau, K., Lea, R., Soto, X., Nardeosingh, S., Schweickert, A., Amaya, E., Thornton, D. J. and Papalopulu, N. (2014). A secretory cell type develops alongside multiciliated cells, ionocytes and goblet cells, and provides a protective, anti-infective function in the frog embryonic mucociliary epidermis. Development 141, 1514-1525. 
Eid, S. R. and Brandli, A. W. (2001). Xenopus Na,K-ATPase: primary sequence of the beta2 subunit and in situ localization of alpha1, beta1, and gamma expression during pronephric kidney development. Differentiation; research in biological diversity 68, 115-125.

Ezhkova, E., Pasolli, H. A., Parker, J. S., Stokes, N., Su, I. H., Hannon, G., Tarakhovsky, A. and Fuchs, E. (2009). Ezh2 orchestrates gene expression for the stepwise differentiation of tissue-specific stem cells. Cell 136, 11221135.

Filoni, S., Bernardini, S., Cannata, S. M. and D'Alessio, A. (1997). Lens regeneration in larval Xenopus laevis: experimental analysis of the decline in the regenerative capacity during development. Dev Biol 187, 13-24.

Francesconi, C. M., Hutcheon, A. E., Chung, E. H., Dalbone, A. C., Joyce, N. C. and Zieske, J. D. (2000). Expression patterns of retinoblastoma and E2F family proteins during corneal development. Invest Ophthalmol Vis Sci 41, 1054-1062.

Freeman, G. (1963). Lens Regeneration from the Cornea in Xenopus Laevis. J Exp Zool 154, 39-65.

Fukui, L. and Henry, J. J. (2011). FGF signaling is required for lens regeneration in Xenopus laevis. Biol Bull 221, 137-145.

Furlow, J. D., Berry, D. L., Wang, Z. and Brown, D. D. (1997). A set of novel tadpole specific genes expressed only in the epidermis are down-regulated by thyroid hormone during Xenopus laevis metamorphosis. Dev Biol 182, 284298.

Gargioli, C., Giambra, V., Santoni, S., Bernardini, S., Frezza, D., Filoni, S. and Cannata, S. M. (2008). The lens-regenerating competence in the outer cornea and epidermis of larval Xenopus laevis is related to pax6 expression. Journal of anatomy 212, 612-620.

Goldberg, M. F. and Bron, A. J. (1982). Limbal palisades of Vogt. Transactions of the American Ophthalmological Society 80, 155-171.

Griffiths, J. A., Scialdone, A. and Marioni, J. C. (2018). Using single-cell genomics to understand developmental processes and cell fate decisions. Mol Syst Biol 14, e8046.

Guo, Z. H., Zhang, W., Jia, Y. Y. S., Liu, Q. X., Li, Z. F. and Lin, J. S. (2018). An Insight into the Difficulties in the Discovery of Specific Biomarkers of Limbal Stem Cells. Int J Mol Sci 19.

Guzman, A., Ramos-Balderas, J. L., Carrillo-Rosas, S. and Maldonado, E. (2013). A stem cell proliferation burst forms new layers of P63 expressing suprabasal cells during zebrafish postembryonic epidermal development. Biology open 2, 1179-1186.

Haber, A. L., Biton, M., Rogel, N., Herbst, R. H., Shekhar, K., Smillie, C., Burgin, G., Delorey, T. M., Howitt, M. R., Katz, Y., et al. (2017). A single-cell survey of the small intestinal epithelium. Nature 551, 333-339.

Haensel, D., Jin, S., Sun, P., Cinco, R., Dragan, M., Nguyen, Q., Cang, Z., Gong, Y., Vu, R., MacLean, A. L., et al. (2020). Defining Epidermal Basal Cell States during Skin Homeostasis and Wound Healing Using Single-Cell Transcriptomics. Cell reports 30, 3932-3947 e3936.

Hamilton, P. W. and Henry, J. J. (2016). The lens regenerative competency of limbal vs. central regions of mature Xenopus cornea epithelium. Exp Eye Res 152, 94-99. 
Hamilton, P. W., Sun, Y. and Henry, J. J. (2016). Lens regeneration from the cornea requires suppression of Wnt/beta-catenin signaling. Exp Eye Res 145, 206-215.

Hans, F. and Dimitrov, S. (2001). Histone H3 phosphorylation and cell division. Oncogene 20, 3021-3027.

Henry, J. J., Carinato, M. E., Schaefer, J. J., Wolfe, A. D., Walter, B. E., Perry, K. J. and Elbl, T. N. (2002). Characterizing gene expression during lens formation in Xenopus laevis: Evaluating the model for embryonic lens induction. Developmental Dynamics 224, 168-185.

Henry, J. J., Perry, K. J. and Hamilton, P. W. (2018). Ex Vivo Eye Tissue Culture Methods for Xenopus. Cold Spring Harb Protoc.

Henry, J. J., Wever, J. M., Natalia Vergara, M. and Fukui, L. (2008). Chapter 6 Xenopus, an Ideal Vertebrate System for Studies of Eye Development and Regeneration A2 - Tsonis, Panagiotis A. In Animal Models in Eye Research, pp. 57-92. London: Academic Press.

Hu, W., Haamedi, N., Lee, J., Kinoshita, T. and Ohnuma, S. (2013). The structure and development of Xenopus laevis cornea. Exp Eye Res 116, 109-128.

Irvine, A. D., Coleman, C. M., Moore, J. E., Swensson, O., Morgan, S. J., McCarthy, J. H., Smith, F. J., Black, G. C. and McLean, W. H. (2002). A novel mutation in KRT12 associated with Meesmann's epithelial corneal dystrophy. Br J Ophthalmol 86, 729-732.

Irvine, A. D., Corden, L. D., Swensson, O., Swensson, B., Moore, J. E., Frazer, D. G., Smith, F. J., Knowlton, R. G., Christophers, E., Rochels, R., et al. (1997). Mutations in cornea-specific keratin K3 or K12 genes cause Meesmann's corneal dystrophy. Nature genetics 16, 184-187.

Joost, S., Zeisel, A., Jacob, T., Sun, X., La Manno, G., Lonnerberg, P., Linnarsson, S. and Kasper, M. (2016). Single-Cell Transcriptomics Reveals that Differentiation and Spatial Signatures Shape Epidermal and Hair Follicle Heterogeneity. Cell Syst 3, 221-237 e229.

Kammergruber, E., Rahn, C., Nell, B., Gabner, S. and Egerbacher, M. (2019). Morphological and immunohistochemical characteristics of the equine corneal epithelium. Vet Ophthalmol 22, 778-790.

Kaplan, N., Wang, J., Wray, B., Patel, P., Yang, W., Peng, H. and Lavker, R. M. (2019). Single-Cell RNA Transcriptome Helps Define the Limbal/Corneal Epithelial Stem/Early Transit Amplifying Cells and How Autophagy Affects This Population. Invest Ophthalmol Vis Sci 60, 3570-3583.

Karimi, K., Fortriede, J. D., Lotay, V. S., Burns, K. A., Wang, D. Z., Fisher, M. E., Pells, T. J., James-Zorn, C., Wang, Y., Ponferrada, V. G., et al. (2018). Xenbase: a genomic, epigenomic and transcriptomic model organism database. Nucleic Acids Res 46, D861-D868.

Kawasaki, A., Kumasaka, M., Satoh, A., Suzuki, M., Tamura, K., Goto, T., Asashima, M. and Yamamoto, H. (2008). Mitf contributes to melanosome distribution and melanophore dendricity. Pigment cell \& melanoma research 21, 56-62.

Keyes, B. E., Segal, J. P., Heller, E., Lien, W. H., Chang, C. Y., Guo, X., Oristian, D. S., Zheng, D. and Fuchs, E. (2013). Nfatc1 orchestrates aging in hair follicle stem cells. Proc Natl Acad Sci U S A 110, E4950-4959.

Kha, C. X., Son, P. H., Lauper, J. and Tseng, K. A. (2018). A model for investigating developmental eye repair in Xenopus laevis. Exp Eye Res 169, 38-47. 
Kim, H. Y., Jackson, T. R., Stuckenholz, C. and Davidson, L. A. (2020). Tissue mechanics drives regeneration of a mucociliated epidermis on the surface of Xenopus embryonic aggregates. Nature communications 11, 665.

Kinoshita, S., Friend, J. and Thoft, R. A. (1981). Sex chromatin of donor corneal epithelium in rabbits. Invest Ophthalmol Vis Sci 21, 434-441.

Klein, A. M., Mazutis, L., Akartuna, I., Tallapragada, N., Veres, A., Li, V., Peshkin, L., Weitz, D. A. and Kirschner, M. W. (2015). Droplet barcoding for single-cell transcriptomics applied to embryonic stem cells. Cell 161, 11871201.

Klein, R. H., Hu, W., Kashgari, G., Lin, Z., Nguyen, T., Doan, M. and Andersen, B. (2017). Characterization of enhancers and the role of the transcription factor KLF7 in regulating corneal epithelial differentiation. J Biol Chem 292, 18937-18950.

Klintworth, G. K. (2009). Corneal dystrophies. Orphanet J Rare Dis 4, 7.

Kumar, P., Tan, Y. and Cahan, P. (2017). Understanding development and stem cells using single cell-based analyses of gene expression. Development 144 , 17-32.

Kumasaka, M., Sato, S., Yajima, I. and Yamamoto, H. (2003). Isolation and developmental expression of tyrosinase family genes in Xenopus laevis. Pigment Cell Res 16, 455-462.

Lavker, R. M., Kaplan, N., Wang, J. and Peng, H. (2020). Corneal epithelial biology: Lessons stemming from old to new. Exp Eye Res, 108094.

Lavker, R. M., Tseng, S. C. and Sun, T. T. (2004). Corneal epithelial stem cells at the limbus: looking at some old problems from a new angle. Exp Eye Res 78, 433-446.

Lay, K., Kume, T. and Fuchs, E. (2016). FOXC1 maintains the hair follicle stem cell niche and governs stem cell quiescence to preserve long-term tissueregenerating potential. Proc Natl Acad Sci U S A 113, E1506-1515.

Lehrer, M. S., Sun, T. T. and Lavker, R. M. (1998). Strategies of epithelial repair: modulation of stem cell and transit amplifying cell proliferation. Journal of cell science 111 ( Pt 19), 2867-2875.

Lescroart, F., Wang, X., Lin, X., Swedlund, B., Gargouri, S., Sanchez-Danes, A., Moignard, V., Dubois, C., Paulissen, C., Kinston, S., et al. (2018). Defining the earliest step of cardiovascular lineage segregation by single-cell RNA-seq. Science 359, 1177-1181.

Li, J., Xiao, Y., Coursey, T. G., Chen, X., Deng, R., Lu, F., Pflugfelder, S. C. and Li, D. Q. (2017). Identification for Differential Localization of Putative Corneal Epithelial Stem Cells in Mouse and Human. Sci Rep 7, 5169.

Liao, Y., Chang, H. C., Liang, F. X., Chung, P. J., Wei, Y., Nguyen, T. P., Zhou, G., Talebian, S., Krey, L. C., Deng, F. M., et al. (2018). Uroplakins play conserved roles in egg fertilization and acquired additional urothelial functions during mammalian divergence. Molecular biology of the cell 29, 3128-3143.

Liu, N., Matsumura, H., Kato, T., Ichinose, S., Takada, A., Namiki, T., Asakawa, K., Morinaga, H., Mohri, Y., De Arcangelis, A., et al. (2019). Stem cell competition orchestrates skin homeostasis and ageing. Nature 568, 344-350.

Llorens-Bobadilla, E., Zhao, S., Baser, A., Saiz-Castro, G., Zwadlo, K. and Martin-Villalba, A. (2015). Single-Cell Transcriptomics Reveals a Population of Dormant Neural Stem Cells that Become Activated upon Brain Injury. Cell Stem Cell 17, 329-340. 
Ma, J. and Lwigale, P. (2019). Transformation of the Transcriptomic Profile of Mouse Periocular Mesenchyme During Formation of the Embryonic Cornea. Invest Ophthalmol Vis Sci 60, 661-676.

Macosko, E. Z., Basu, A., Satija, R., Nemesh, J., Shekhar, K., Goldman, M., Tirosh, I., Bialas, A. R., Kamitaki, N., Martersteck, E. M., et al. (2015). Highly Parallel Genome-wide Expression Profiling of Individual Cells Using Nanoliter Droplets. Cell 161, 1202-1214.

Majo, F., Rochat, A., Nicolas, M., Jaoude, G. A. and Barrandon, Y. (2008). Oligopotent stem cells are distributed throughout the mammalian ocular surface. Nature 456, 250-254.

Mariani, R. A., Paranjpe, S., Dobrowolski, R. and Weber, G. F. (2020). 14-3-3 targets keratin intermediate filaments to mechanically sensitive cell-cell contacts. Molecular biology of the cell 31, 930-943.

Matsumura, H., Mohri, Y., Binh, N. T., Morinaga, H., Fukuda, M., Ito, M., Kurata, S., Hoeijmakers, J. and Nishimura, E. K. (2016). Hair follicle aging is driven by transepidermal elimination of stem cells via COL17A1 proteolysis. Science 351, aad4395.

Morita, M., Fujita, N., Takahashi, A., Nam, E. R., Yui, S., Chung, C. S., Kawahara, N., Lin, H. Y., Tsuzuki, K., Nakagawa, T., et al. (2015). Evaluation of ABCG2 and p63 expression in canine cornea and cultivated corneal epithelial cells. Vet Ophthalmol 18, 59-68.

Moriyama, M., Durham, A. D., Moriyama, H., Hasegawa, K., Nishikawa, S., Radtke, F. and Osawa, M. (2008). Multiple roles of Notch signaling in the regulation of epidermal development. Dev Cell 14, 594-604.

Mort, R. L., Douvaras, P., Morley, S. D., Dora, N., Hill, R. E., Collinson, J. M. and West, J. D. (2012). Stem cells and corneal epithelial maintenance: insights from the mouse and other animal models. Results Probl Cell Differ 55, 357394.

Nakatsu, M. N., Ding, Z., Ng, M. Y., Truong, T. T., Yu, F. and Deng, S. X. (2011). Wnt/beta-catenin signaling regulates proliferation of human cornea epithelial stem/progenitor cells. Invest Ophthalmol Vis Sci 52, 4734-4741.

Nakayama, T., Fisher, M., Nakajima, K., Odeleye, A. O., Zimmerman, K. B., Fish, M. B., Yaoita, Y., Chojnowski, J. L., Lauderdale, J. D., Netland, P. A., et al. (2015). Xenopus pax6 mutants affect eye development and other organ systems, and have phenotypic similarities to human aniridia patients. Dev Biol 408, 328-344.

Nenni, M. J., Fisher, M. E., James-Zorn, C., Pells, T. J., Ponferrada, V., Chu, S., Fortriede, J. D., Burns, K. A., Wang, Y., Lotay, V. S., et al. (2019). Xenbase: Facilitating the Use of Xenopus to Model Human Disease. Front Physiol 10, 154.

Nieuwkoop, P. D. and Faber, J. (1956). Normal table of Xenopus laevis (Daudin). 162-203.

Norman, B., Davis, J. and Piatigorsky, J. (2004). Postnatal gene expression in the normal mouse cornea by SAGE. Invest Ophthalmol Vis Sci 45, 429-440.

Nowell, C. S. and Radtke, F. (2017). Corneal epithelial stem cells and their niche at a glance. Journal of cell science 130, 1021-1025.

Ortiz-Melo, M. T., Sanchez-Guzman, E., Gonzalez-Robles, A., Valdes, J., Gomez-Flores, E. and Castro-Munozledo, F. (2013). Expression of claudins -2 and -4 and cingulin is coordinated with the start of stratification and 
differentiation in corneal epithelial cells: retinoic acid reversibly disrupts epithelial barrier. Biology open 2, 132-143.

Park, J., Shrestha, R., Qiu, C., Kondo, A., Huang, S., Werth, M., Li, M., Barasch, J. and Susztak, K. (2018). Single-cell transcriptomics of the mouse kidney reveals potential cellular targets of kidney disease. Science 360, 758-763.

Perry, K. J., Thomas, A. G. and Henry, J. J. (2013). Expression of pluripotency factors in larval epithelia of the frog Xenopus: evidence for the presence of cornea epithelial stem cells. Dev Bio/ 374, 281-294.

Pfirrmann, T., Emmerich, D., Ruokonen, P., Quandt, D., Buchen, R., FischerZirnsak, B., Hecht, J., Krawitz, P., Meyer, P., Klopocki, E., et al. (2015). Molecular mechanism of CHRDL1-mediated X-linked megalocornea in humans and in Xenopus model. Hum Mol Genet 24, 3119-3132.

Ramms, L., Fabris, G., Windoffer, R., Schwarz, N., Springer, R., Zhou, C., Lazar, J., Stiefel, S., Hersch, N., Schnakenberg, U., et al. (2013). Keratins as the main component for the mechanical integrity of keratinocytes. Proc Natl Acad Sci U S A 110, 18513-18518.

Romano, R. A., Smalley, K., Magraw, C., Serna, V. A., Kurita, T., Raghavan, S. and Sinha, S. (2012). DeltaNp63 knockout mice reveal its indispensable role as a master regulator of epithelial development and differentiation. Development 139, 772-782.

Sartaj, R., Zhang, C., Wan, P., Pasha, Z., Guaiquil, V., Liu, A., Liu, J., Luo, Y., Fuchs, E. and Rosenblatt, M. I. (2017). Characterization of slow cycling corneal limbal epithelial cells identifies putative stem cell markers. Sci Rep 7, 3793.

Satija, R., Farrell, J. A., Gennert, D., Schier, A. F. and Regev, A. (2015). Spatial reconstruction of single-cell gene expression data. Nat Biotechnol 33, 495502.

Schermer, A., Galvin, S. and Sun, T. T. (1986). Differentiation-related expression of a major $64 \mathrm{~K}$ corneal keratin in vivo and in culture suggests limbal location of corneal epithelial stem cells. The Journal of Cell Biology 103, 49-62.

Schlotzer-Schrehardt, U. and Kruse, F. E. (2005). Identification and characterization of limbal stem cells. Exp Eye Res 81, 247-264.

Schmiesing, J. A., Gregson, H. C., Zhou, S. and Yokomori, K. (2000). A human condensin complex containing hCAP-C-hCAP-E and CNAP1, a homolog of Xenopus XCAP-D2, colocalizes with phosphorylated histone H3 during the early stage of mitotic chromosome condensation. Molecular and cellular biology 20, 6996-7006.

Schreiber, A. M. and Brown, D. D. (2003). Tadpole skin dies autonomously in response to thyroid hormone at metamorphosis. Proc Natl Acad Sci U S A 100, 1769-1774.

Session, A. M., Uno, Y., Kwon, T., Chapman, J. A., Toyoda, A., Takahashi, S., Fukui, A., Hikosaka, A., Suzuki, A., Kondo, M., et al. (2016). Genome evolution in the allotetraploid frog Xenopus laevis. Nature 538, 336-343.

Slack, J. M. (1984). Regional biosynthetic markers in the early amphibian embryo. $J$ Embryol Exp Morphol 80, 289-319.

Sonam, S., Srnak, J. A., Perry, K. J. and Henry, J. J. (2019). Molecular markers for corneal epithelial cells in larval vs. adult Xenopus frogs. Exp Eye Res 184, 107-125. 
1134

1135

1136

1137

1138

1139

1140

1141

1142

1143

1144

1145

1146

1147

1148

1149

1150

1151

1152

1153

1154

1155

1156

1157

1158

1159

1160

1161

1162

1163

1164

1165

1166

1167

1168

1169

1170

1171

1172

1173

1174

1175

1176

1177

1178

1179

1180

1181

1182

Stephens, D. N., Klein, R. H., Salmans, M. L., Gordon, W., Ho, H. and Andersen, B. (2013). The Ets transcription factor EHF as a regulator of cornea epithelial cell identity. J Biol Chem 288, 34304-34324.

Sun, T. T. and Lavker, R. M. (2004). Corneal epithelial stem cells: past, present, and future. J Investig Dermatol Symp Proc 9, 202-207.

Suzuki, K., Machiyama, F., Nishino, S., Watanabe, Y., Kashiwagi, K., Kashiwagi, A. and Yoshizato, K. (2009). Molecular features of thyroid hormoneregulated skin remodeling in Xenopus laevis during metamorphosis. Development, growth \& differentiation 51, 411-427.

Swamynathan, S. K. (2013). Ocular surface development and gene expression. $J$ Ophthalmol 2013, 103947.

Tandon, P., Conlon, F., Furlow, J. D. and Horb, M. E. (2017). Expanding the genetic toolkit in Xenopus: Approaches and opportunities for human disease modeling. Dev Biol 426, 325-335.

Thoft, R. A. and Friend, J. (1983). The X, Y, Z hypothesis of corneal epithelial maintenance. Invest Ophthalmol Vis Sci 24, 1442-1443.

Thomas, A. G. and Henry, J. J. (2014). Retinoic acid regulation by CYP26 in vertebrate lens regeneration. Dev Biol 386, 291-301.

Trapnell, C., Cacchiarelli, D., Grimsby, J., Pokharel, P., Li, S., Morse, M., Lennon, N. J., Livak, K. J., Mikkelsen, T. S. and Rinn, J. L. (2014). The dynamics and regulators of cell fate decisions are revealed by pseudotemporal ordering of single cells. Nat Biotechnol 32, 381-386.

Tseng, A. S. (2017). Seeing the future: using Xenopus to understand eye regeneration. Genesis 55.

Tseng, S. C. (1989). Concept and application of limbal stem cells. Eye (London, England) 3 ( Pt 2), 141-157.

Viet, J., Reboutier, D., Hardy, S., Lachke, S. A., Paillard, L. and GautierCourteille, C. (2020). Modeling ocular lens disease in Xenopus. Dev Dyn 249, 610-621.

Voigt, A. P., Mulfaul, K., Mullin, N. K., Flamme-Wiese, M. J., Giacalone, J. C., Stone, E. M., Tucker, B. A., Scheetz, T. E. and Mullins, R. F. (2019). Single-cell transcriptomics of the human retinal pigment epithelium and choroid in health and macular degeneration. Proc Natl Acad Sci U S A 116, 24100-24107.

Walentek, P. and Quigley, I. K. (2017). What we can learn from a tadpole about ciliopathies and airway diseases: Using systems biology in Xenopus to study cilia and mucociliary epithelia. Genesis $\mathbf{5 5}$.

Watanabe, M., Yasuoka, Y., Mawaribuchi, S., Kuretani, A., Ito, M., Kondo, M., Ochi, H., Ogino, H., Fukui, A., Taira, M., et al. (2017). Conservatism and variability of gene expression profiles among homeologous transcription factors in Xenopus laevis. Dev Biol 426, 301-324.

Watanabe, Y., Kobayashi, H., Suzuki, K., Kotani, K. and Yoshizato, K. (2001). New epidermal keratin genes from Xenopus laevis: hormonal and regional regulation of their expression during anuran skin metamorphosis. Biochimica et biophysica acta 1517, 339-350.

Wiechmann, A. F., Ceresa, B. P. and Howard, E. W. (2014). Diurnal variation of tight junction integrity associates inversely with matrix metalloproteinase expression in Xenopus laevis corneal epithelium: implications for circadian regulation of homeostatic surface cell desquamation. PLoS One 9, e113810. 
Wu, B., An, C., Li, Y., Yin, Z., Gong, L., Li, Z., Liu, Y., Heng, B. C., Zhang, D., Ouyang, H., et al. (2017). Reconstructing Lineage Hierarchies of Mouse Uterus Epithelial Development Using Single-Cell Analysis. Stem cell reports $\mathbf{9}$, 381-396.

Yam, G. H. F., Riau, A. K., Funderburgh, M. L., Mehta, J. S. and Jhanji, V. (2020). Keratocyte biology. Exp Eye Res, 108062.

Yi, X., Wang, Y. and Yu, F. S. (2000). Corneal epithelial tight junctions and their response to lipopolysaccharide challenge. Invest Ophthalmol Vis Sci 41, 4093-4100.

Yoon, J. J., Ismail, S. and Sherwin, T. (2014). Limbal stem cells: Central concepts of corneal epithelial homeostasis. World Journal of Stem Cells 6, 391-403.

Yoshida, N., Yoshida, S., Araie, M., Handa, H. and Nabeshima, Y. (2000). Ets family transcription factor ESE-1 is expressed in corneal epithelial cells and is involved in their differentiation. Mechanisms of development 97, 27-34.

Yoshida, Y., Ban, Y. and Kinoshita, S. (2009). Tight junction transmembrane protein claudin subtype expression and distribution in human corneal and conjunctival epithelium. Invest Ophthalmol Vis Sci 50, 2103-2108.

Yoshihara, M., Hara, S., Tsujikawa, M., Kawasaki, S., Hayashizaki, Y., Itoh, M., Kawaji, H. and Nishida, K. (2017). Restricted Presence of POU6F2 in Human Corneal Endothelial Cells Uncovered by Extension of the Promoterlevel Expression Atlas. EBioMedicine 25, 175-186.

Yoshihara, M., Ohmiya, H., Hara, S., Kawasaki, S., consortium, F., Hayashizaki, Y., Itoh, M., Kawaji, H., Tsujikawa, M. and Nishida, K. (2015). Discovery of molecular markers to discriminate corneal endothelial cells in the human body. PLoS One 10, e0117581.

Yoshizato, K. (2007). Molecular mechanism and evolutional significance of epithelial-mesenchymal interactions in the body- and tail-dependent metamorphic transformation of anuran larval skin. Int Rev Cytol 260, 213-260.

Zhao, J., Mo, V. and Nagasaki, T. (2009). Distribution of Label-retaining Cells in the Limbal Epithelium of a Mouse Eye. Journal of Histochemistry \& Cytochemistry 57, 177-185.

Zheng, G. X., Terry, J. M., Belgrader, P., Ryvkin, P., Bent, Z. W., Wilson, R., Ziraldo, S. B., Wheeler, T. D., McDermott, G. P., Zhu, J., et al. (2017). Massively parallel digital transcriptional profiling of single cells. Nature communications 8, 14049.

Zhou, F., Li, X., Wang, W., Zhu, P., Zhou, J., He, W., Ding, M., Xiong, F., Zheng, X., Li, Z., et al. (2016). Tracing haematopoietic stem cell formation at singlecell resolution. Nature 533, 487-492.

Zhou, M., Li, X. M. and Lavker, R. M. (2006). Transcriptional profiling of enriched populations of stem cells versus transient amplifying cells. A comparison of limbal and corneal epithelial basal cells. J Biol Chem 281, 19600-19609. 
A

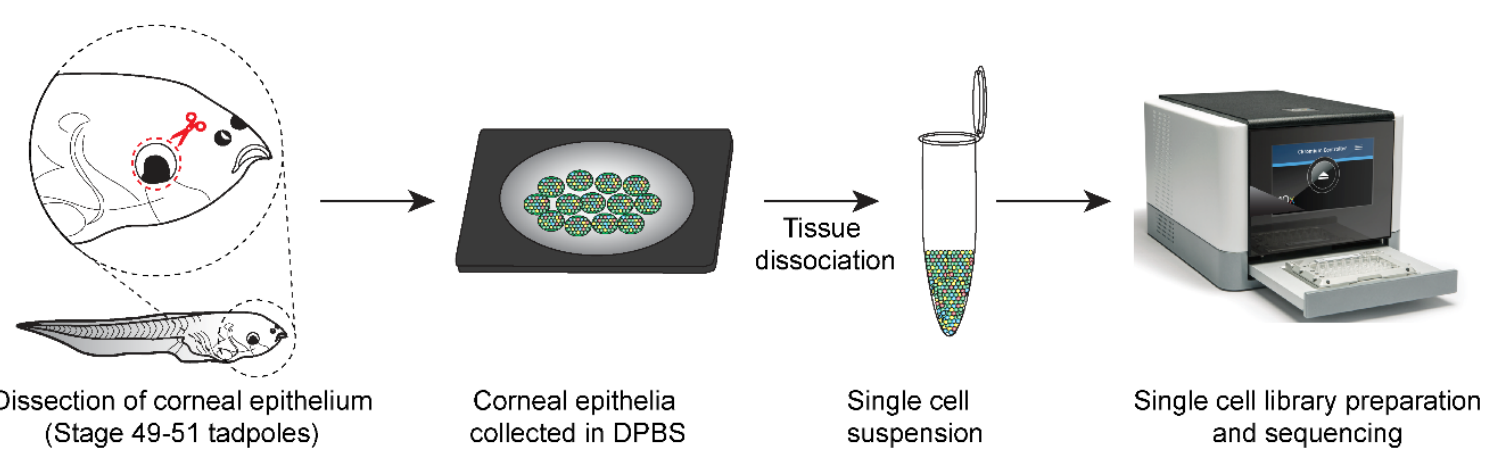

B

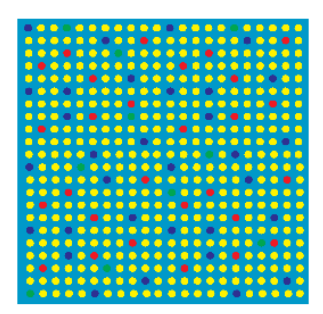

Cell $x$ Gene Matrix

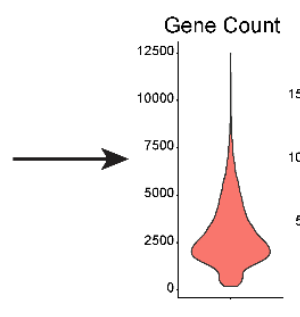

Basic QC

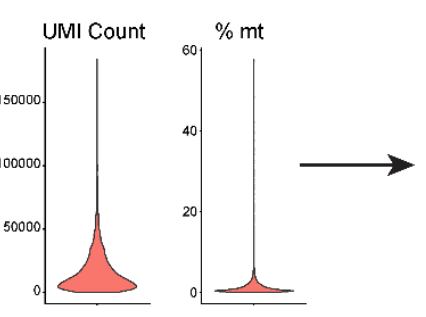

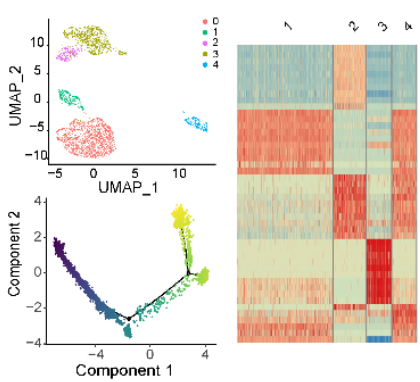

Data analysis

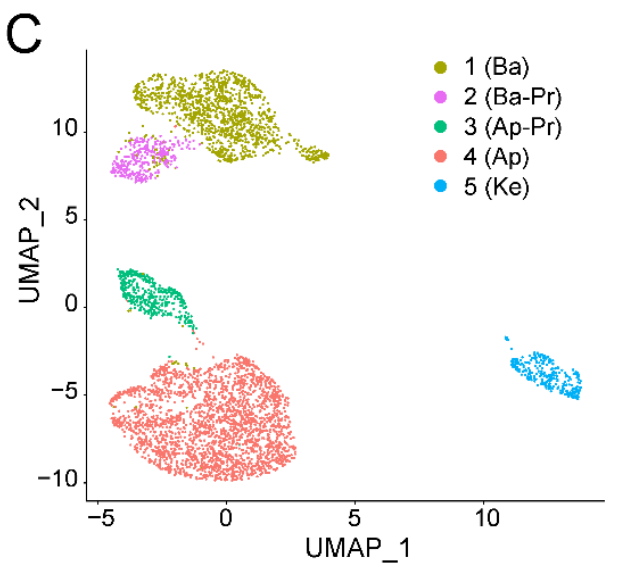

1225

1226

1227

1228

1229

1230

1231

1232

1233

1234

1235

1236

D

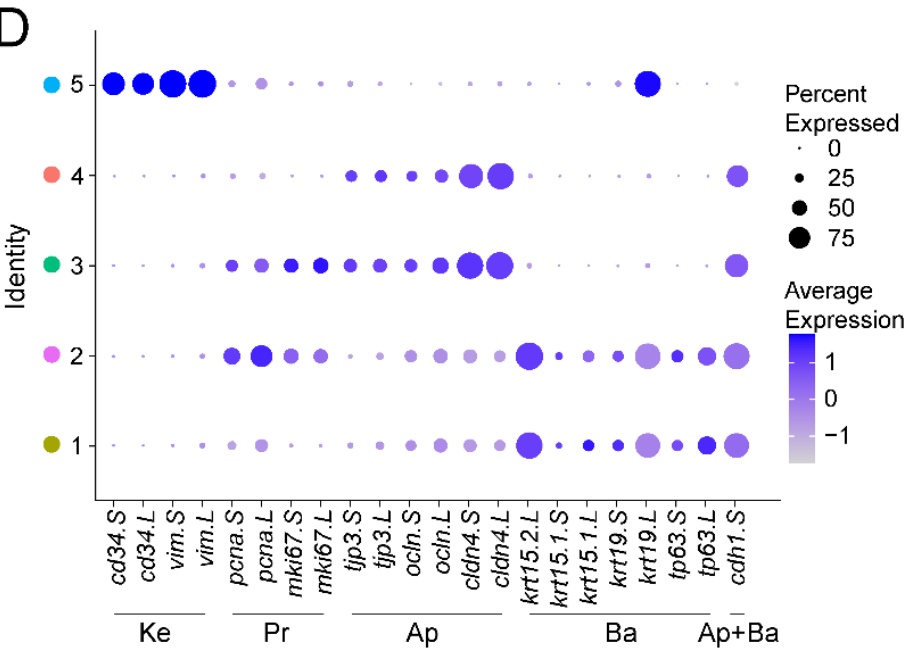

Fig. 1. Single-cell RNA sequencing analysis of corneal cells from Xenopus

laevis tadpoles. (A) Overview detailing physical workflow for isolation of corneal epithelial cells for single-cell RNA sequencing (scRNA-seq). Corneal epithelial tissues were dissected from each tadpole, collectively pooled (in DPBS) and enzymatically dissociated to isolate single corneal cells. After determining cell viability, a single-cell library was prepared from the suspension using the $10 \mathrm{X}$ Chromium Single Cell 3' Reagent Kit (V3 chemistry). (B) Computational workflow depicting the data processing and analysis pipeline for scRNA-seq data. Cell Ranger was used to align raw reads and generate feature-barcode matrices from the scRNA-seq output. Seurat v3.1 was used to perform basic QC (see Table S2). (C) Unbiased clustering of 4,810 high-quality cells after QC cutoffs, visualized by 
1237 Uniform Manifold Approximation and Projection (UMAP). Each dot represents a

1238 single cell, and cells belonging to the same cluster are similarly colored, as indicated

1239 by the key. (D) Dot plot showing expression of known cell-type marker genes across

1240 cells for each cluster (cell type) identified in the dataset. Dot diameter depicts the

1241 percentage of cluster cells expressing that marker and the color intensity encodes

1242 average expression of a gene among all cells within that cluster, according to the

1243 keys. Abbreviations: Ap: Apical; Ba: Basal; Ke: Keratocytes; Pr: Proliferative; Ap-Pr:

1244 Apical-Proliferative; Ba-Pr: Basal Proliferative; Ap+Ba: Apical and Basal. 
Basal Markers

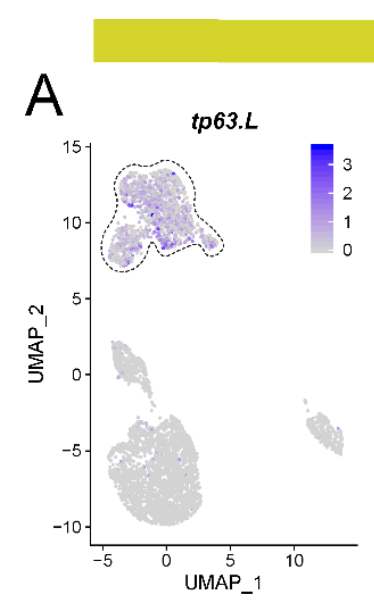

A

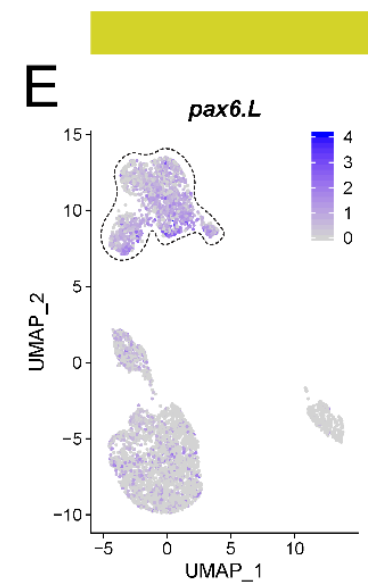

Apical Marker

I

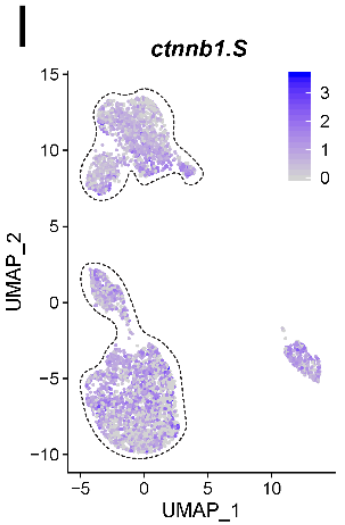

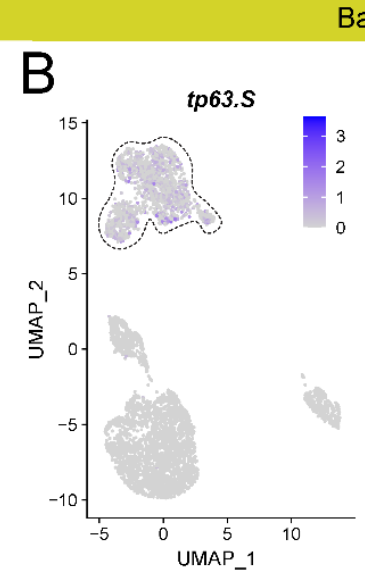

C

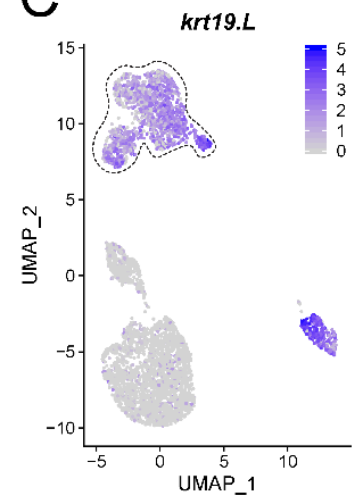

Basal Markers

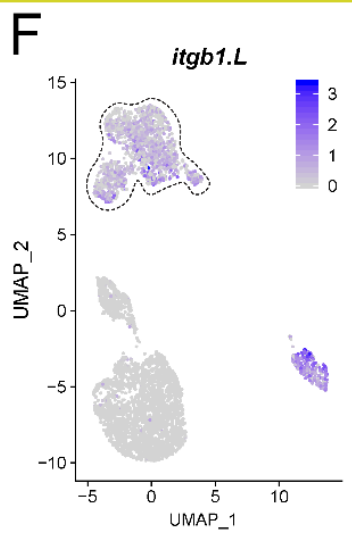

Apical+Basal Marker

$\mathrm{J}$

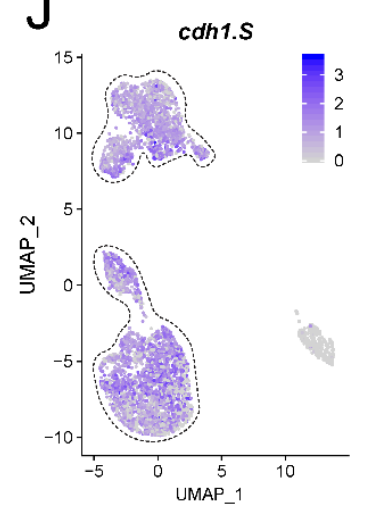

G

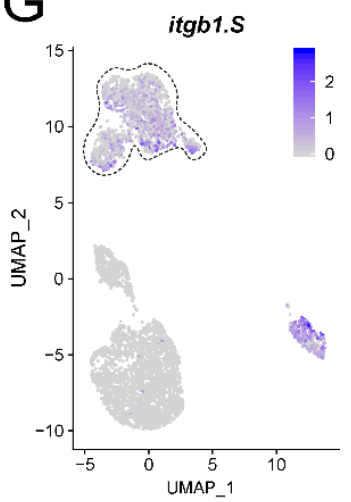

$\mathrm{D}$

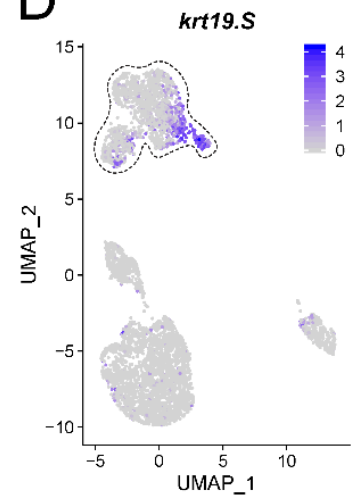

Apical Marker

$\mathrm{H}$

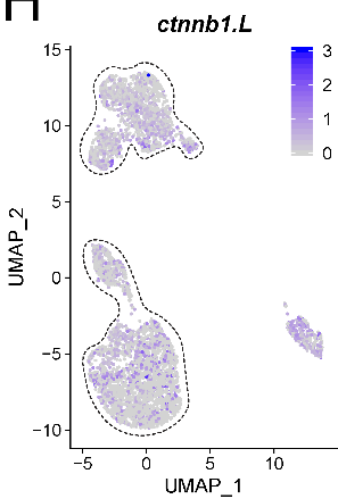

Keratocyte Marker

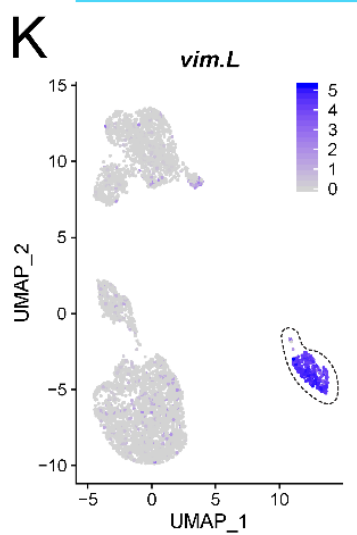

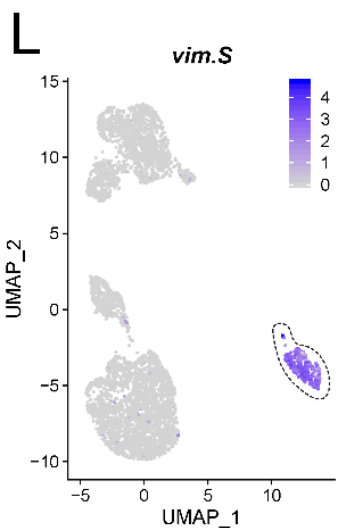

Fig. 2. Cellular heterogeneity of larval frog corneal epithelium. Feature plots

1247 representing gene expression of previously identified (Sonam et al., 2019) Xenopus

1248 cell-type-specific markers that were used for assigning cluster identities. Black

1249 dashed lines highlight clusters with enhanced expression for the indicated genes. (A-

1250 G) Basal epithelial cells (Clusters 1 and 2) were identified based on the expression

1251 of genes tp63.L, tp63.S, krt19.L, krt19.S, pax6.L, itgb1.L and itgb1.S. (H-I) Gene

1252 beta-catenin (ctnnb1.L and ctnnb1.S) was used as an apical marker based on our

1253 previous immunolocalization study; however, transcripts were found to be expressed

1254 in both apical and basal cells (Clusters 1-4). (J) cdh1.S was expressed in both apical 
1255 and basal cells (Clusters 1-4). (K-L) Corneal keratocytes (Cluster 5) were identified

1256 based on the expression of vim.L and vim.S. Color intensity correlates with the

1257 relative transcript level for the indicated gene in each cell, as indicated by the

1258 key. Additional marker gene plots are provided in Fig. S2. 
A

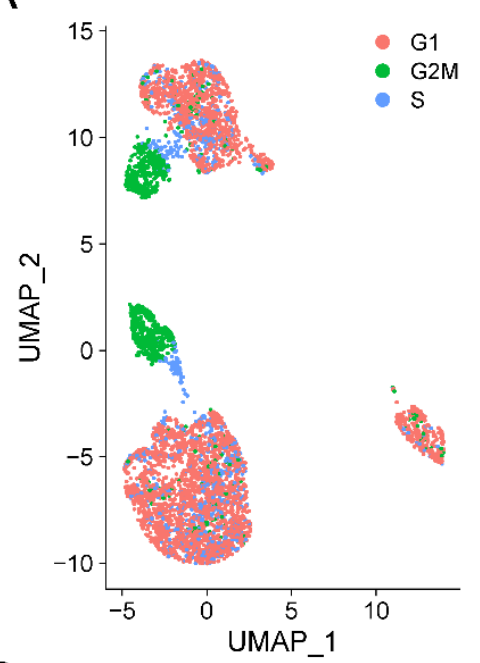

D

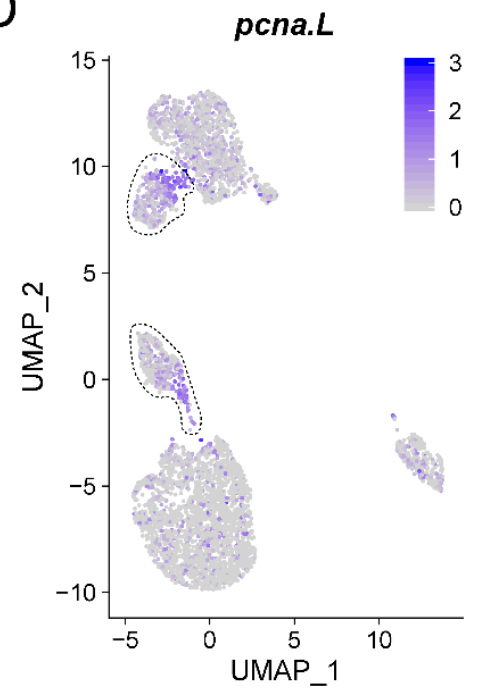

B

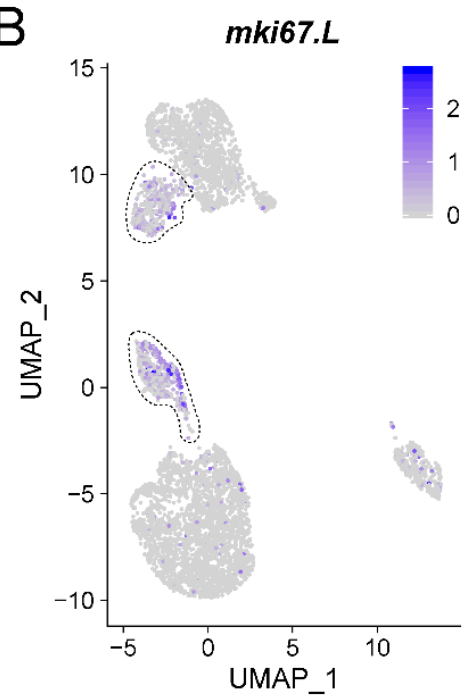

$E$

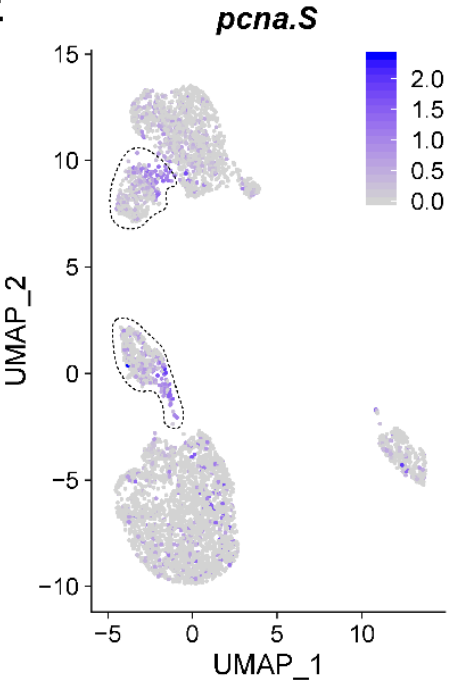

C

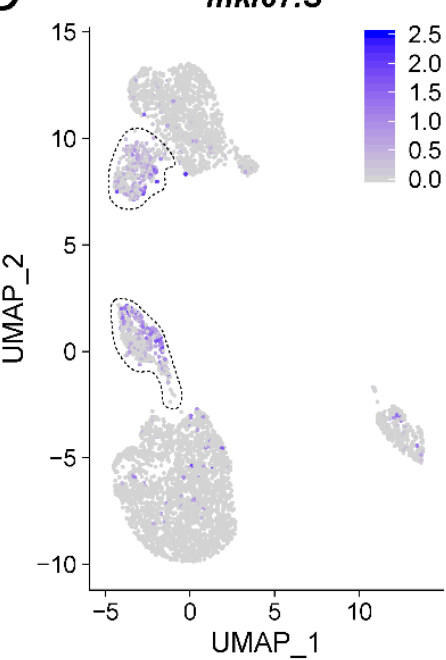

$\mathrm{F}$

top $2 a . L$

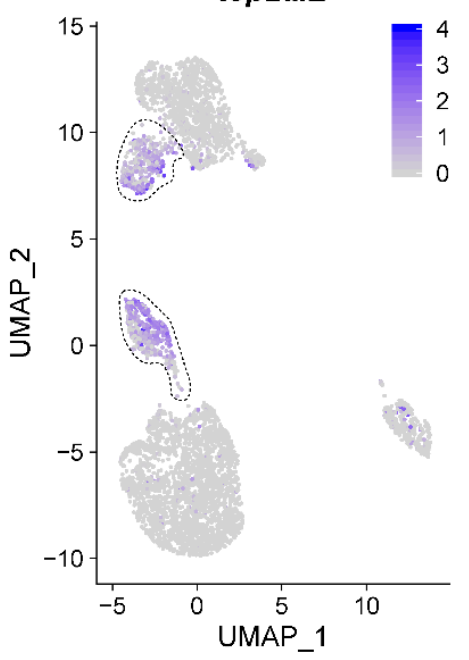

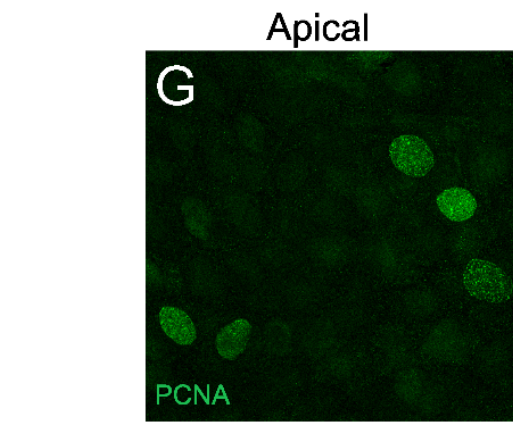
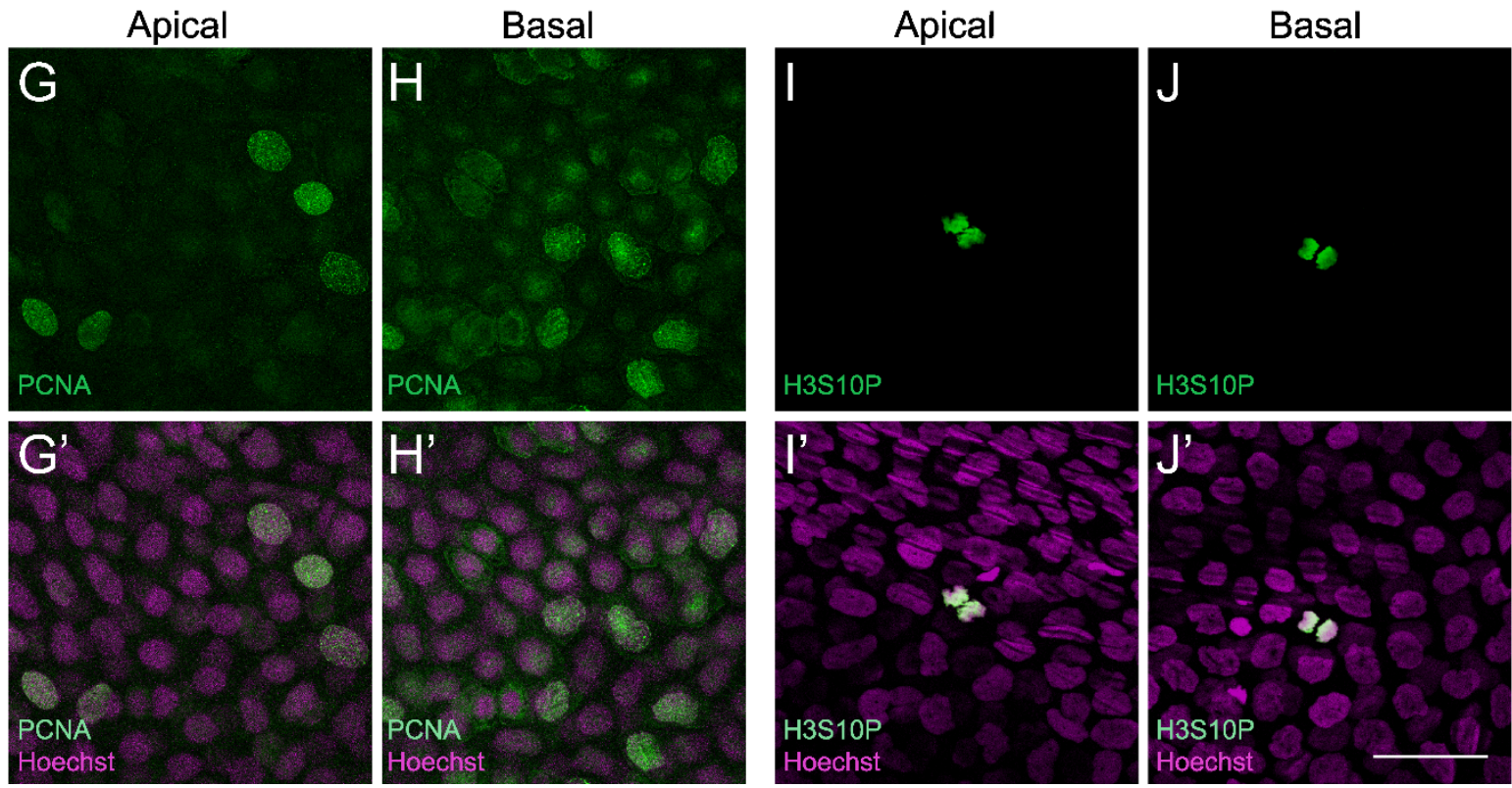

1260 Fig. 3. Proliferative cells reside in the bi-layered corneal epithelium of frog

1261 larvae. (A) UMAP plot showing the cell cycle status of each cell, as determined 
1262 using the "CellCycleScoring" module in Seurat v3.1. The color key indicates the cell

1263 cycle state. (B-F) Gene expression UMAP overlay with proliferation marker genes

1264 mki67.L, mki67.S, pcna.L, pcna.S and top2a.L, respectively. Black dashed lines

1265 highlight clusters for the indicated gene. Color intensity correlates with the relative

1266 transcript level for the indicated gene in each cell, as noted in the key. (G-H)

1267 Confocal microscopic images showing immunofluorescent staining for Proliferating

1268 Cell Nuclear Antigen (PCNA) (green) in the larval frog corneal epithelium. (G'-H')

1269 Merged images for G-H with Hoechst labeled nuclei (magenta). (G, G') Nuclear

1270 staining for PCNA is detected in some apical epithelial cells. $\left(\mathrm{H}, \mathrm{H}^{\prime}\right)$ PCNA labeled

1271 nuclei are also detected in cells of the basal epithelium. (I-J) Confocal microscopic

1272 images showing immunofluorescent labeling for anti-phospho-Histone H3 (H3S10P)

1273 (green) in the tadpole corneal epithelium. (I'-J') Merged images for I-J with Hoechst

1274 labeled nuclei (magenta). (I, I') Mitotic nuclei (H3S10P) are present in a few apical

1275 epithelial cells. (J, J') H3S10P labeled nuclei are also detected in a few cells of the

1276 basal epithelium. Scale bar in J' equals $50 \mu \mathrm{m}$ for G-J and G'-J'. 
A

A

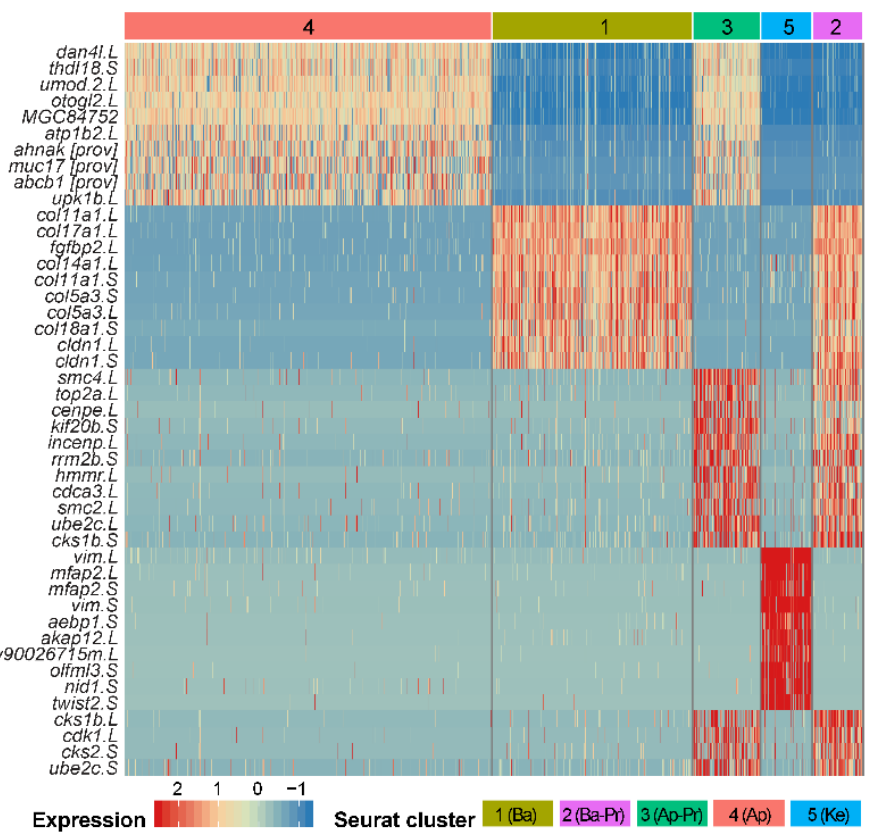

B

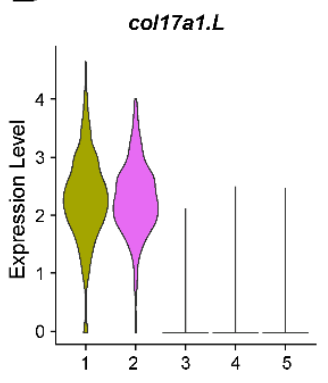

smc4.L
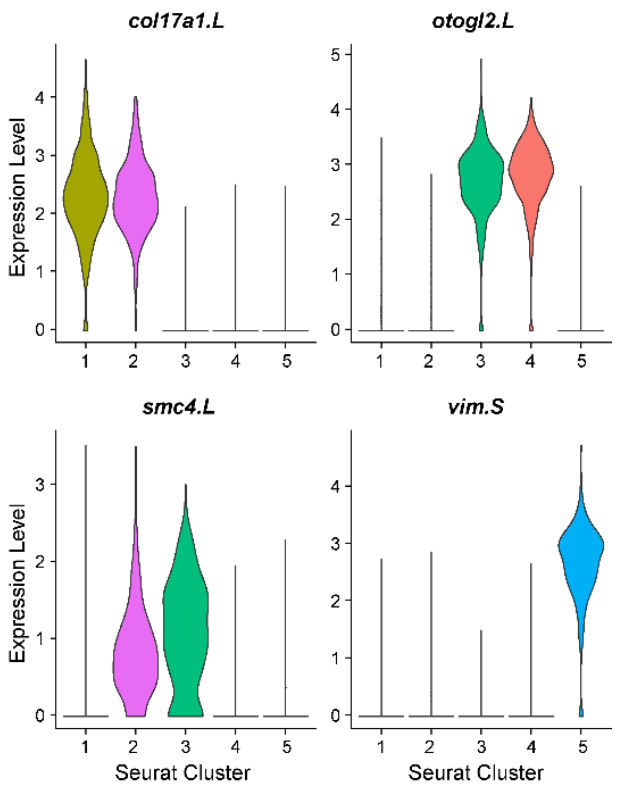

vim.S

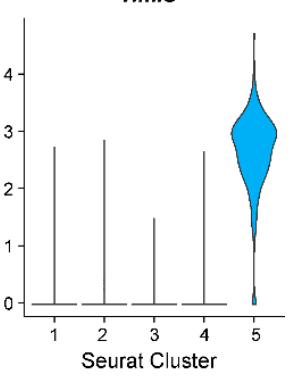

E

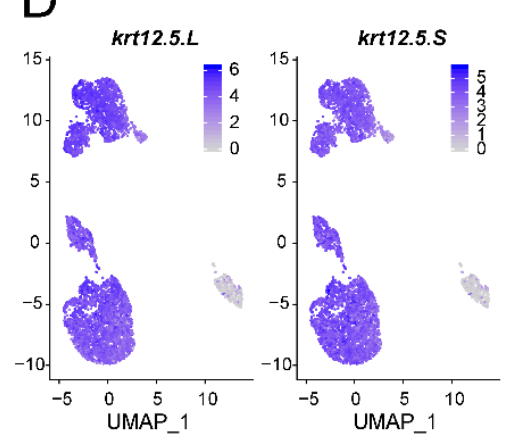

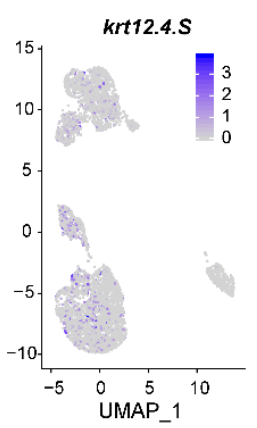

C

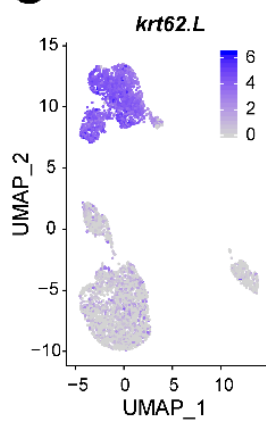

krt62.S

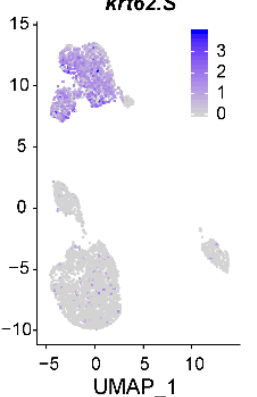

$\mathrm{D}$
E

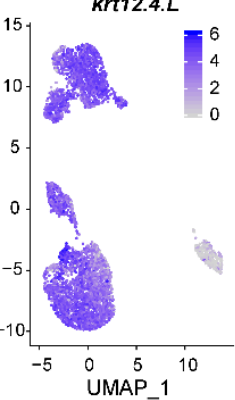

Fig. 4. Identification of novel marker genes for different corneal cell types. (A)

1279 Heatmap showing the cluster-specific expression of the top 10 ranking novel

1280 candidate marker genes for each cell cluster identified in this scRNA-seq dataset.

1281 Relative expression and cluster identity are shown in the key. (B) Violin plots

1282 showing the cluster-specific expression of the top-ranking novel candidate marker

1283 genes for each identified cell type. Color and number correspond to the Seurat

1284 clusters shown in the key in (A). (C-E) Feature plots of .L and .S genes for keratin 62

1285 (krt 62), keratin 12 gene 5 (krt 12.5) and keratin 12 gene 4 (krt12.4), respectively.

1286 Relative expression is indicated in the color key. 

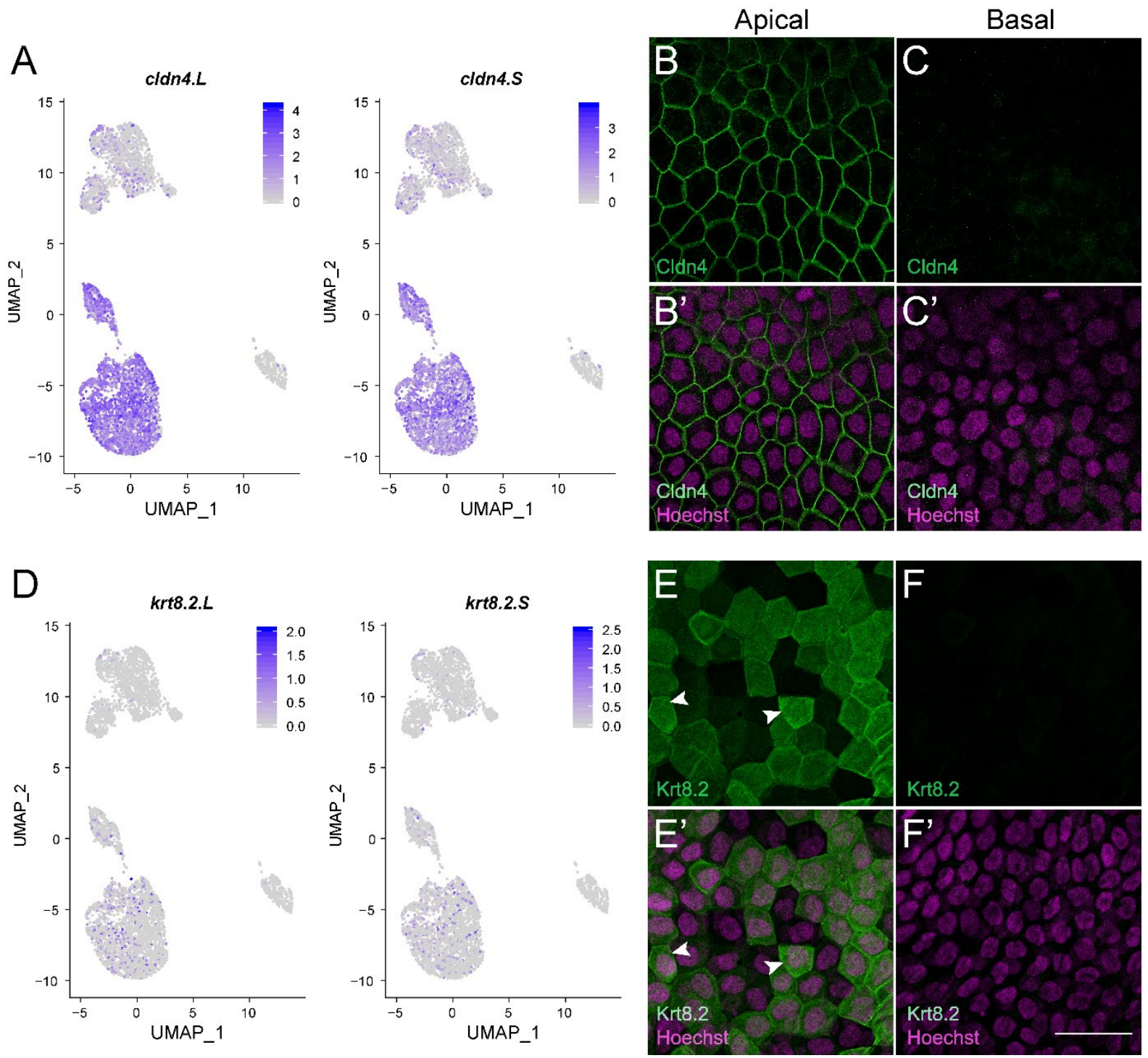

1289 Fig. 5. Validation of newly identified marker genes via protein localization in corneal whole mounts. (A) Feature plots depicting gene expression for claudin 4

1291 (cldn4.L and cldn4.S). Relative expression is indicated in the color key. (B-C)

1292 Confocal microscopic images showing immunofluorescent staining for Cldn4 (green)

1293 in the larval frog corneal epithelium. (B'-C') Merged images for B-C with Hoechst

1294 labeled nuclei (magenta). (B, B') Claudin 4 is uniformly expressed in the membranes

1295 of all epithelial cells of the apical layer. (C, C') No label is detected in the basal

1296 epithelial cells. (D) Feature plots depicting gene expression for keratin 8 (krt8.2.L

1297 and krt8.2.S). Relative expression is indicated in the color key. (E-F) Confocal

1298 microscopic images showing cellular localization of Krt8.2 (green) in the tadpole

1299 corneal epithelium. (E'-F') Merged images for E-F with Hoechst labeled nuclei

1300 (magenta). (E, E') Apical epithelial cells in the cornea show cytoplasmic staining for 
1301 Krt8.2. A mosaic staining pattern is detected, with few cells displaying relatively

1302 higher expression than others (shown by white arrowheads). (F, F') No Krt8.2

1303 staining is present in basal corneal epithelial cells, which agrees with the transcript

1304 expression data. Scale bar in F' equals $50 \mu \mathrm{m}$ for B-C, B'-C', E-F and E'-F'. 


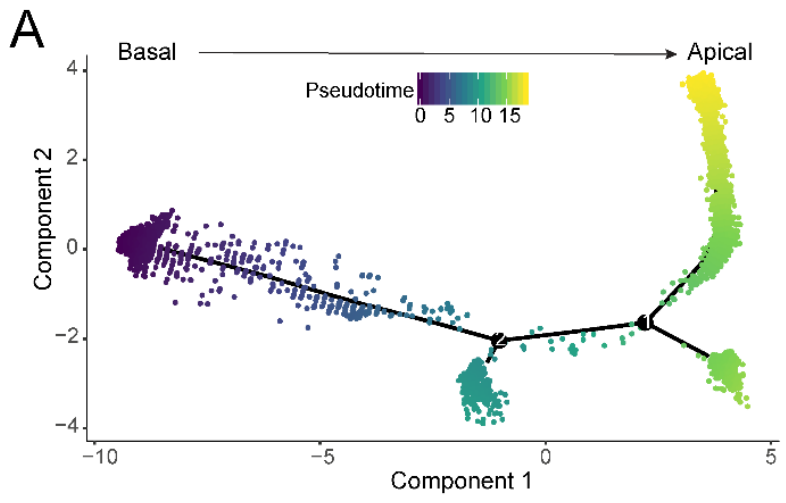

C
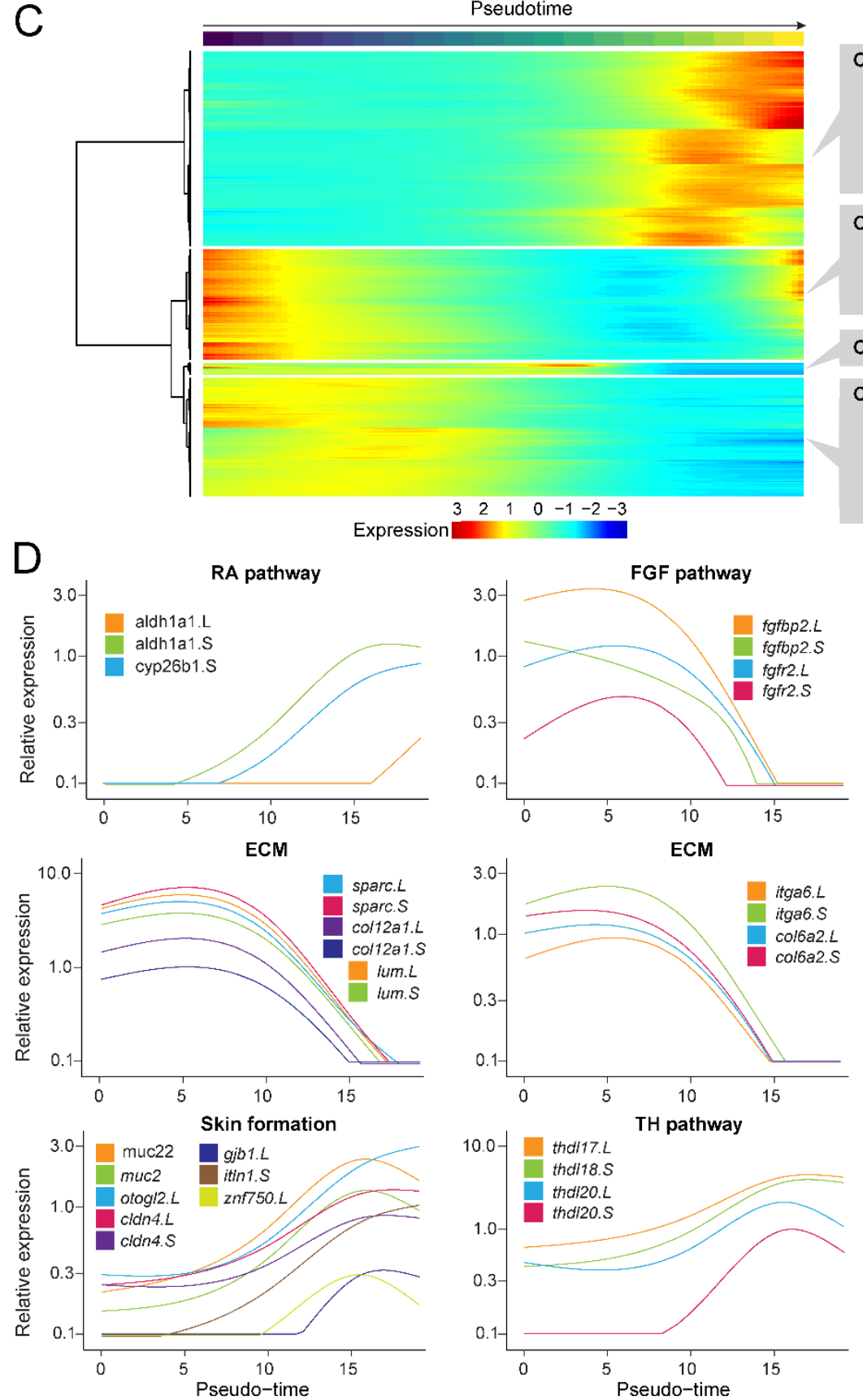

$B$

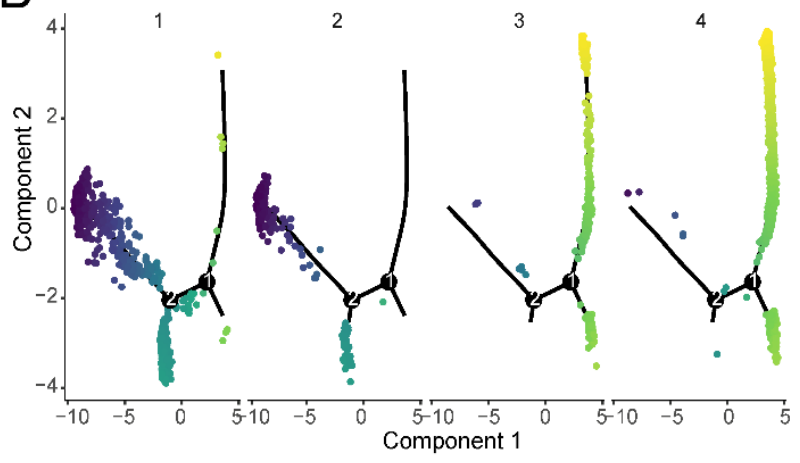

Enriched GO terms

\section{Class A}

- Regulation of NF-kappaB signaling

- MAPK cascade

- EGFR signaling pathway

- Establishment of skin barrier

- Keratinocyte differentiation

\section{Class B}

- Regulation of cell proliferation

- Wnt signaling pathway

- Regulation of apoptotic process

\section{Class C}

Class D

- Extracellular matrix organization

- Cell adhesion

- Integrin-mediated signaling pathway

- Notch signaling pathway

- Epithelial to mesenchymal transition
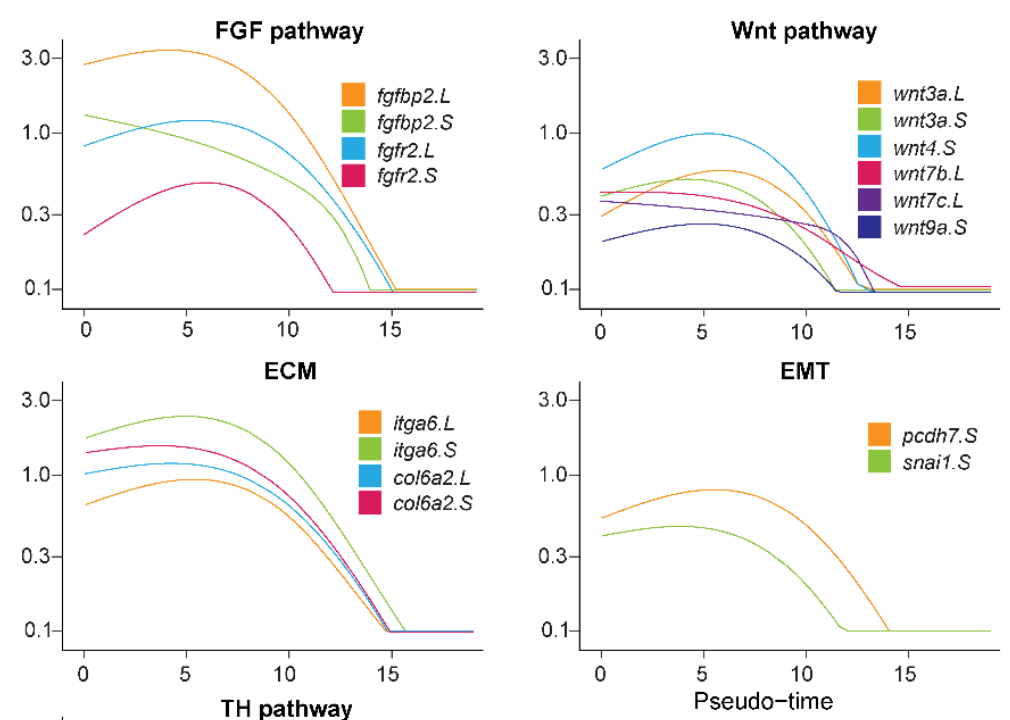

1307 Fig. 6. Pseudo-temporal ordering of individual cells reconstructs the corneal

1308 differentiation process. (A) Pseudo-time plot indicating the cellular trajectory of all 
1309 corneal epithelial cells (Clusters 1-4), excluding the keratocytes. Single-cell

1310 trajectories were constructed, and pseudo-time values were calculated using

1311 Monocle 2. Trajectories are colored by pseudo-time, as indicated in the key. (B)

1312 Pseudo-time plots showing the distribution of each cell type along the combined

1313 cellular trajectories, as demonstrated in (A). Basal epithelial cells (Clusters 1 and 2)

1314 are present early along the trajectory, however, the apical cells (Clusters 3 and 4)

1315 are distributed more towards the end. (C) Heatmap depicting the classes of genes

1316 that vary along the pseudo-time during corneal epithelial differentiation. Pseudo-time

1317 is indicated by the color key similar to that shown in (A). Gene Ontology (GO)

1318 analysis was performed using DAVID and the enriched GO terms $(p<0.05)$ in each

1319 class are listed. Relative expression is indicated by the color key. (D) Gene

1320 expression kinetics along the pseudo-time progression of representative genes

1321 belonging to different pathways and processes, as indicated. Genes shown belong to

1322 the Retinoic Acid pathway (RA pathway), the Fibroblast Growth Factor pathway

1323 (FGF pathway), the Wnt pathway, Extracellular Matrix (ECM) deposition, Epithelial-

1324 to-Mesenchymal Transition (EMT), genes involved in Skin Formation and the Thyroid

1325 Hormone pathway (TH pathway). 

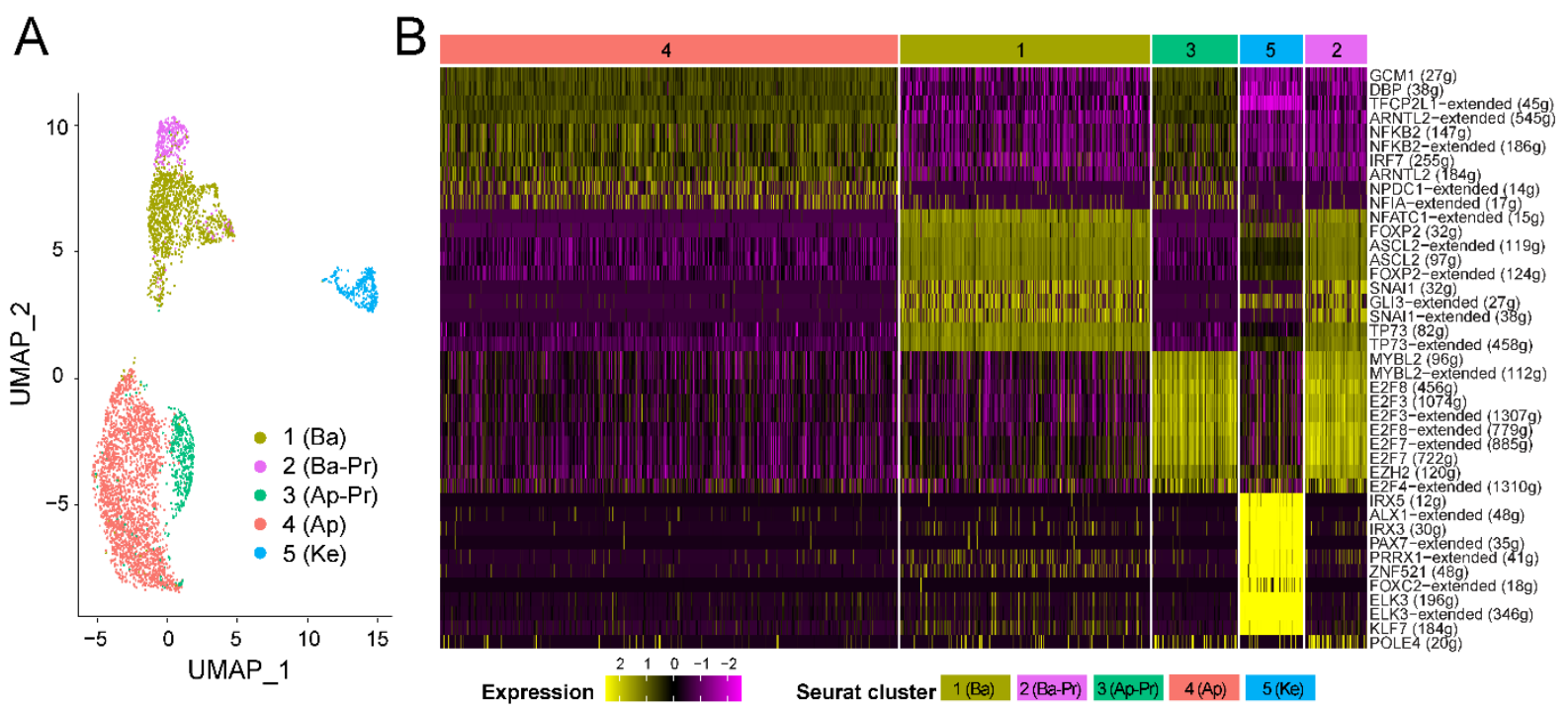

1328 Fig. 7. Distinct gene regulatory networks characterize the corneal cell types.

1329 (A) UMAP clustering of all corneal cells based on the AUC scores for each regulon 1330 calculated using SCENIC. Cells belonging to the same regulon and Seurat cluster 1331 are similarly colored, according to the key. (B) Heatmap depicting the different 1332 regulons that are active in different cell states. Relative expression is shown in the 1333 key. 


\section{SUPPLEMENTARY FIGURES}

A
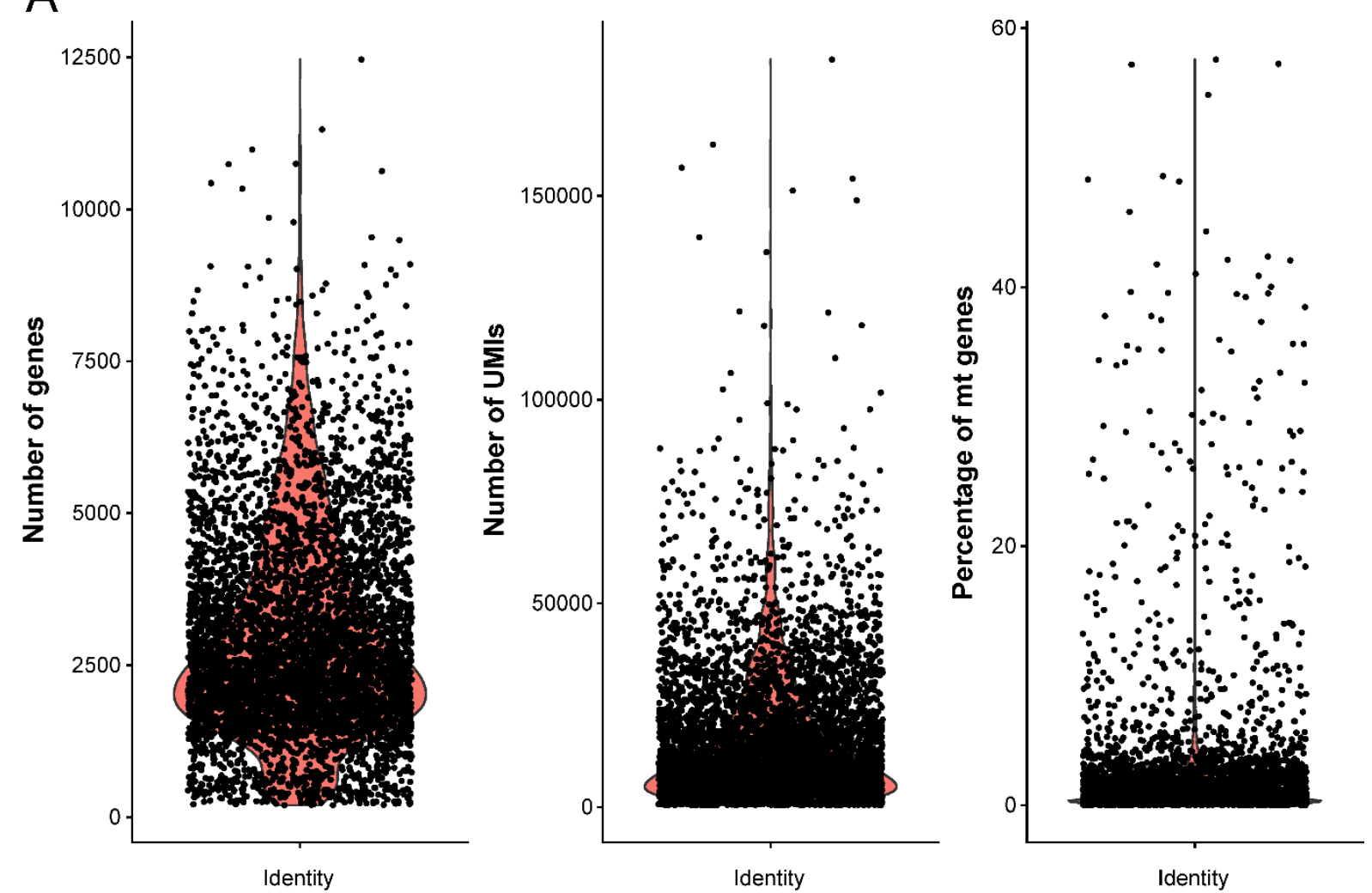

B
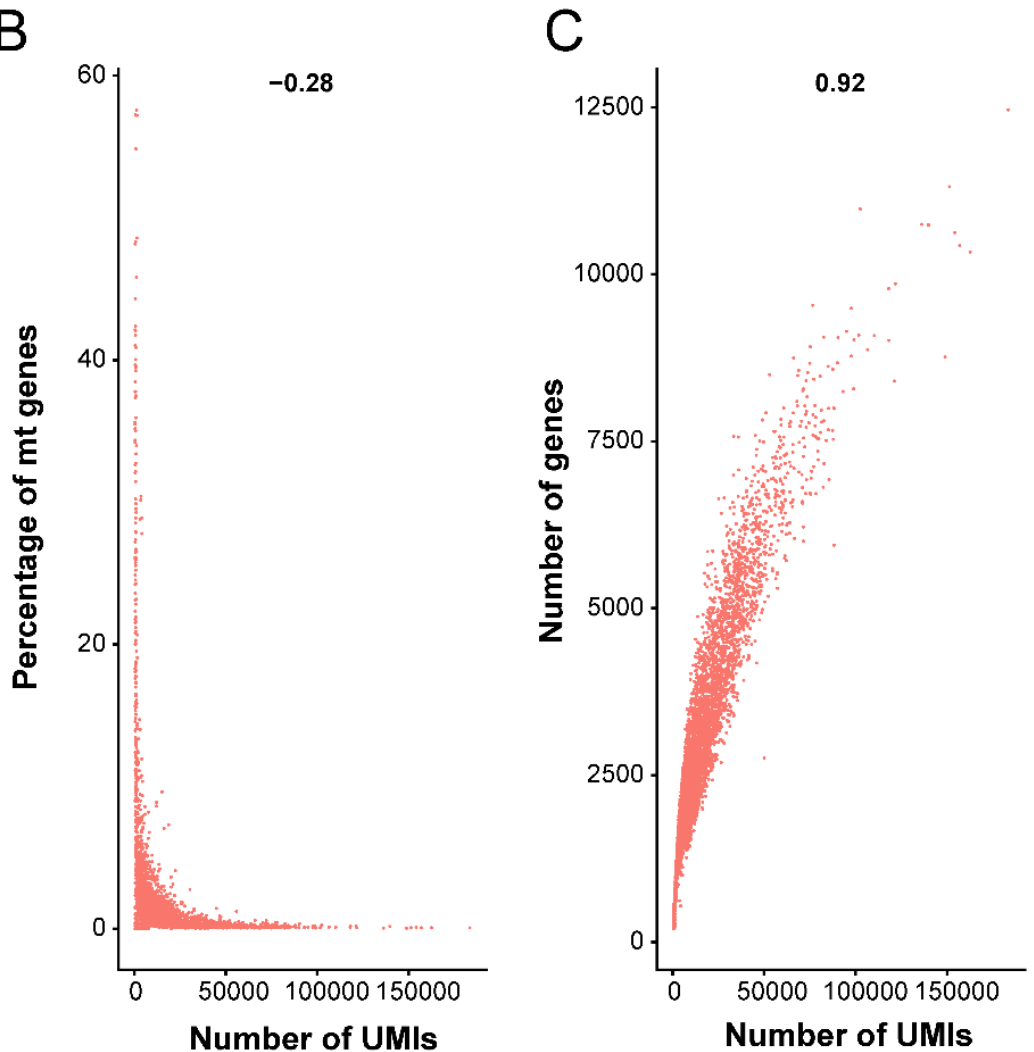

Fig. S1. Quality control (QC) metrics of Xenopus larvae corneal epithelial

scRNA-seq data. (A) Violin plot illustrating the distribution of number of genes, 
1339 unique molecular identifiers (UMIs) and the percentage of mitochondrial (mt) genes,

1340 respectively, in each cell (black dot) of the pooled corneal sample. (B) Scatterplot

1341 showing the correlation of percentage of mitochondrial genes and UMI count. (C)

1342 Scatterplot showing the correlation of number of genes and number of UMIs. 


\section{A}

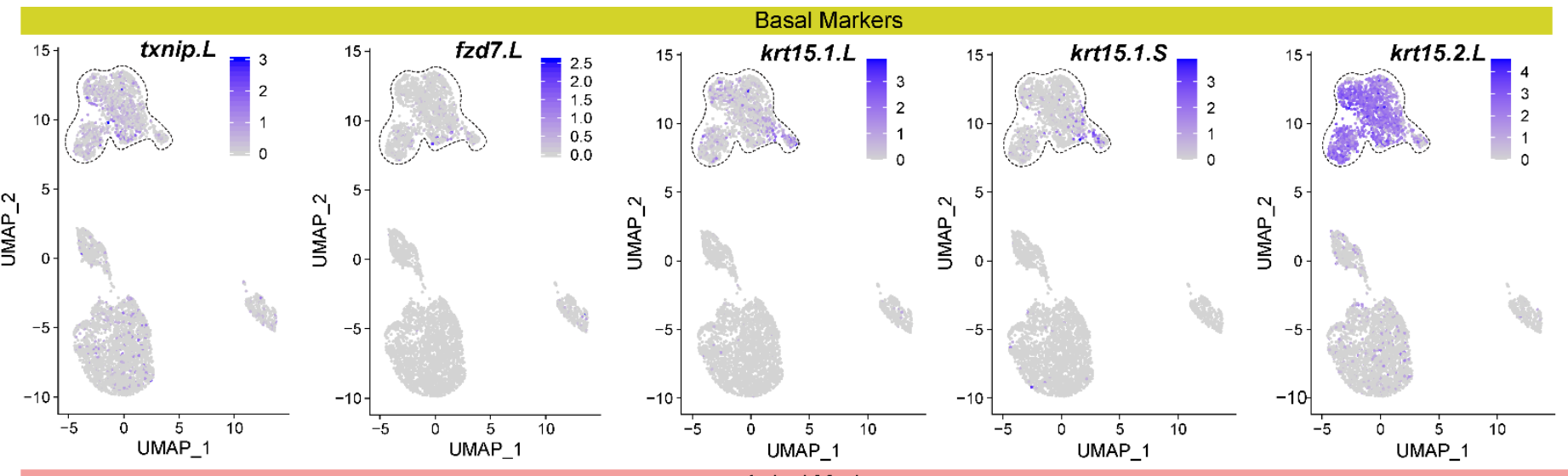

B
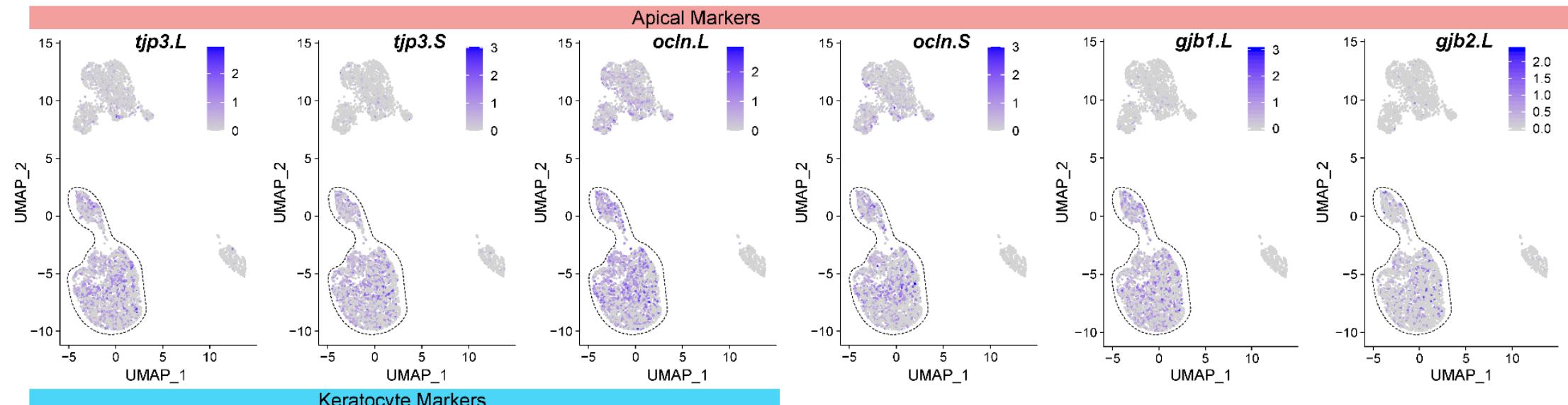

C

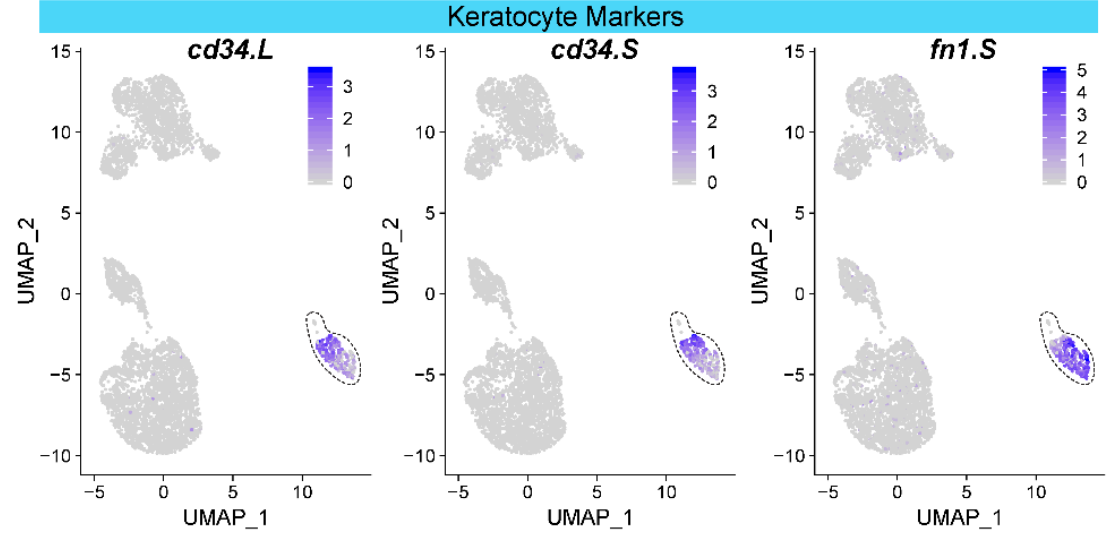

1344 
1345 Fig. S2. (related to Fig. 2) Cell cluster identity was further validated based on

1346 the expression of known marker genes. Feature plots of major cell-type-specific

1347 marker genes, known from the literature (see text). Black dashed lines highlight the

1348 cluster where the indicated gene was more highly expressed. (A) Corneal basal cell

1349 marker genes: thioredoxin interacting protein (txnip.L); frizzled class receptor 7

1350 (fzd7.L); keratin 15 gene 1 (krt15.1.L and krt15.1.S) and keratin 15 gene 2

1351 (krt15.2.L). (B) Apical epithelial cell marker genes: tight junction protein 3 (tjp3.L and

1352 tjp3.S); occludin (ocln.L and ocln.S); gap junction protein beta 1 (gjb1.L) and gap

1353 junction protein beta 2 (gjb2.L). (C) Keratocyte marker genes: CD34 molecule

1354 (cd34.L and cd34.S) and fibronectin 1 (fn1.S). Relative expression is indicated in the 1355 keys. 

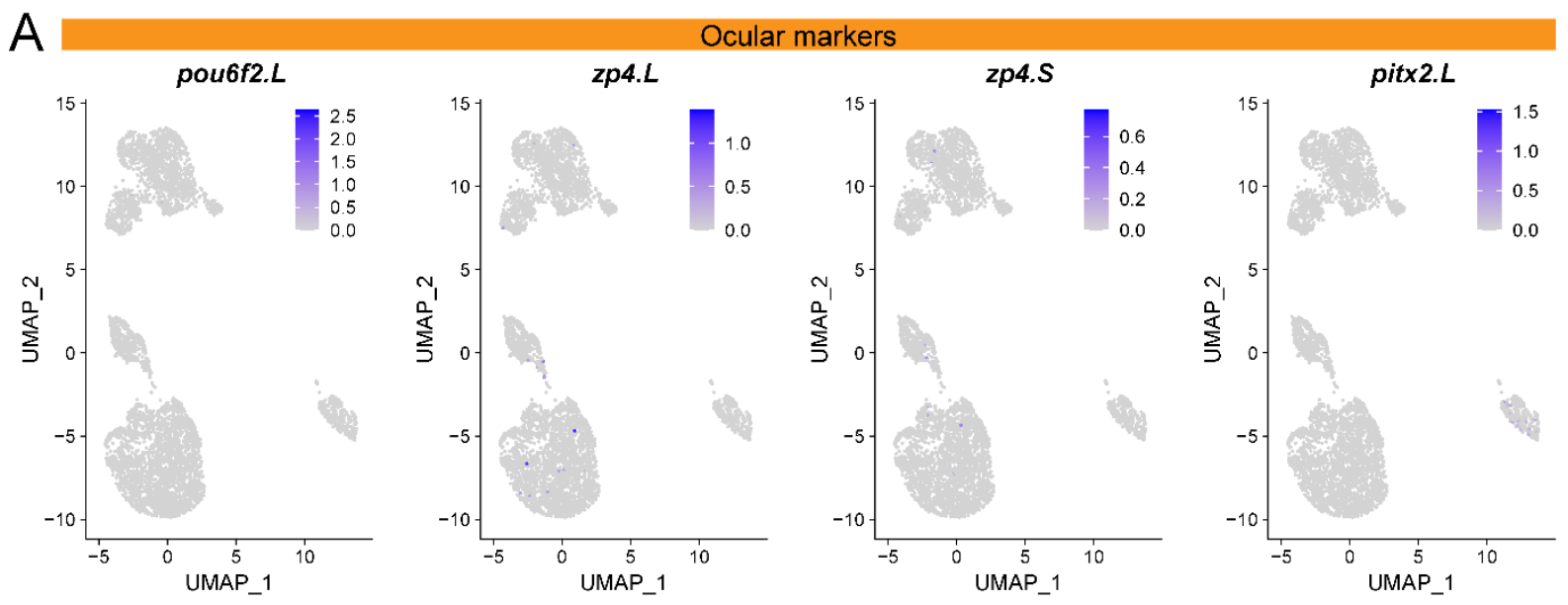

B
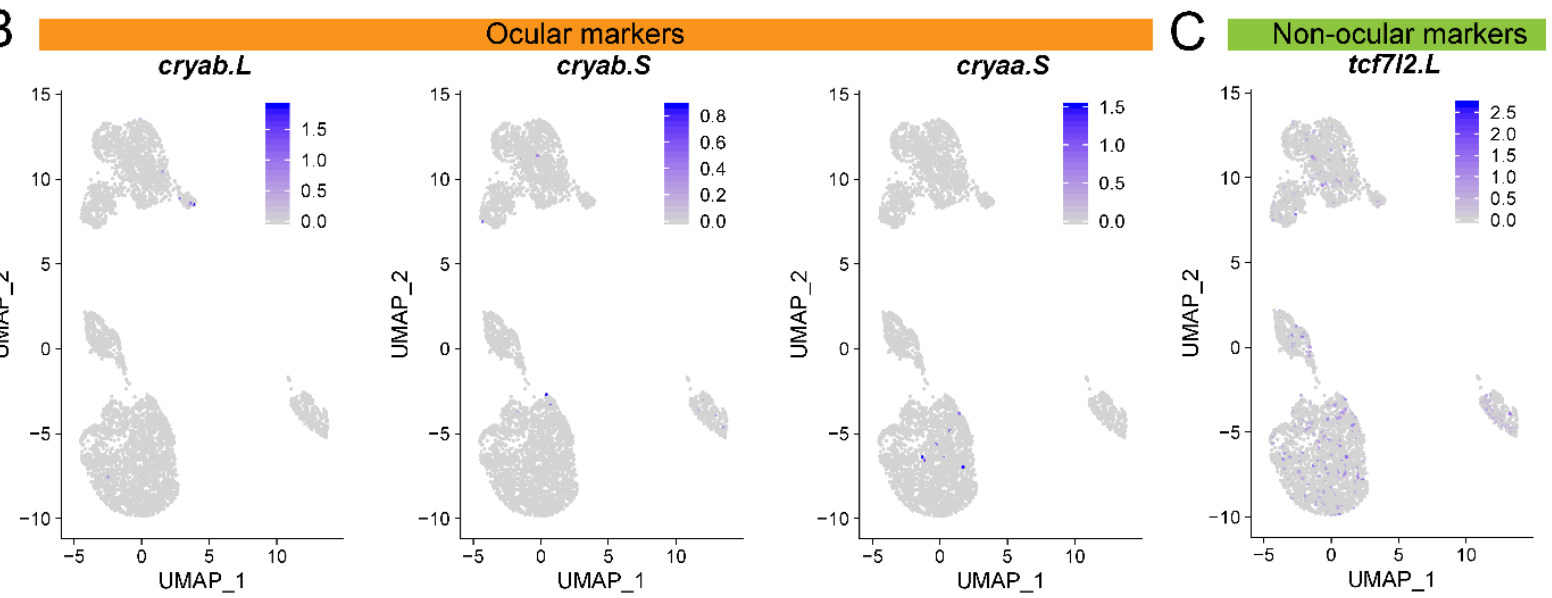

Fig. S3. The absence of other ocular and non-ocular cell types was verified based on the expression of marker genes. Feature plots of cell-type-specific

1360 marker genes. (A) Corneal endothelial marker genes: POU class 6 homeobox 2

1361 (pou6f2.L); zona pellucida glycoprotein 4 (zp4.L and zp4.S) and paired like

1362 homeodomain 2 (pitx2.L). (B) Lens cell marker genes: crystallin alpha B (cryab.L and cryab.S) and crystallin alpha $A$ (cryaa.S).

(C) Marker gene to differentiate cornea

1364 versus skin: transcription factor 7 like 2 (tcf7/2.L). Relative expression is indicated in

1365 the keys. 

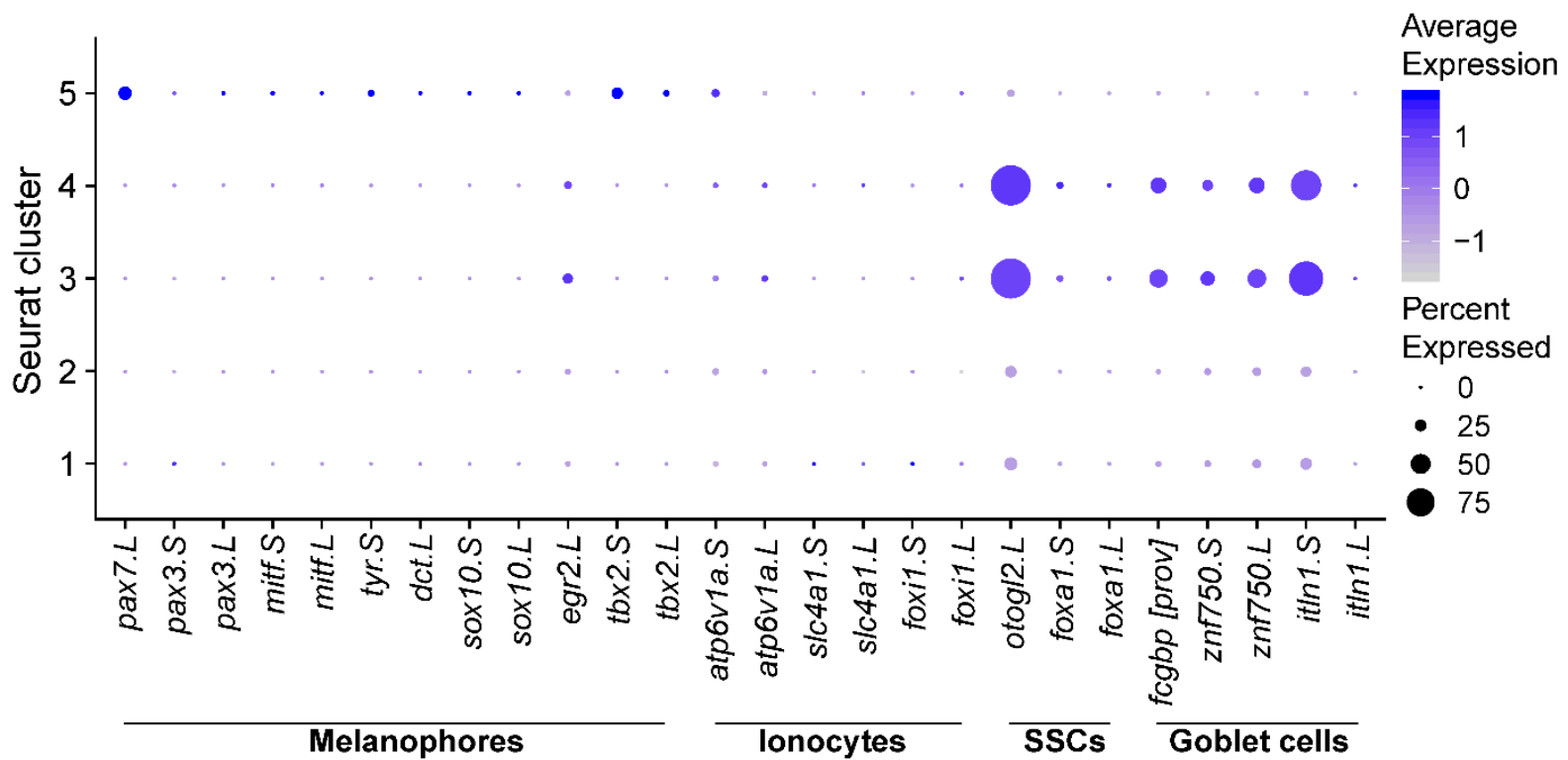

1368 Fig. S4. Cells of the apical corneal epithelium display a Xenopus skin-like

1369 characteristic. Dot plot depicting expression of Xenopus skin cell-types

1370 (Melanophores; lonocytes; Small Secretory Cells, SSCs and Goblet cells) marker

1371 genes across each cluster in the dataset. Marker genes are listed along the $\mathrm{X}$-axis.

1372 Dot diameter depicts the percentage of cluster cells expressing that marker and the

1373 color intensity encodes the average expression of that gene among all cells within

1374 that cluster, according to the keys. 
bioRxiv preprint doi: https://doi.org/10.1101/2020.08.06.240036; this version posted August 6, 2020. The copyright holder for this preprint (which was not certified by peer review) is the author/funder, who has granted bioRxiv a license to display the preprint in perpetuity. It is made available under aCC-BY-NC-ND 4.0 International license.

A

\begin{tabular}{|c|c|c|c|c|}
\hline Ocular Disease & $\begin{array}{c}\text { Disease Ontology ID } \\
\text { (DOID) }\end{array}$ & $\begin{array}{l}\text { Xenopus Gene Name } \\
\text { (Gene Symbol) }\end{array}$ & $\begin{array}{c}\text { Human } \\
\text { homologue }\end{array}$ & Reference \\
\hline $\begin{array}{c}\text { Congenital stromal corneal } \\
\text { dystrophy }\end{array}$ & DOID:0060445 & decorin (dcn) & $D C N$ & $\begin{array}{l}\text { Bredrup et al., 2005; } \\
\text { Bredrup et al., } 2010\end{array}$ \\
\hline $\begin{array}{l}\text { Posterior amorphous corneal } \\
\text { dystrophy }\end{array}$ & $\mathrm{N} / \mathrm{A}$ & lumican (lum) & LUM & $\begin{array}{l}\text { Chakravarti et al., 2000; } \\
\text { Kim et al., } 2014\end{array}$ \\
\hline $\begin{array}{c}\text { Congenital hereditary endothelial } \\
\text { dystrophy of cornea }\end{array}$ & DOID:0060649 & $\begin{array}{l}\text { solute camier family } 4 \\
\text { member } 11 \text { (slc } 4 a 11)\end{array}$ & SLC4A11 & $\begin{array}{l}\text { Han et al., 2013; } \\
\text { Malhotra et al., } 2019\end{array}$ \\
\hline Keratoconus & $\mathrm{N} / \mathrm{A}$ & $\begin{array}{c}\text { superoxide dismutase } 1 \\
\text { (sod1) }\end{array}$ & SOD1 & Udar et al., 2006 \\
\hline Cornea plana & DOID:0060287 & keratocan & $K E R A$ & $\begin{array}{l}\text { Pellegata et al., } 2000 ; \\
\text { Roos et. al., } 2015\end{array}$ \\
\hline Meesmann corneal dystrophy & DOID:0060451 & $\begin{array}{l}\text { keratin } 12, \text { gene } 5(k n 12.5) ; \\
\text { keratin 12, gene } 4(k n t 12.4)\end{array}$ & KRT12 & $\begin{array}{l}\text { Irvine et al., } 1997 \\
\text { Irvine et al., } 2002\end{array}$ \\
\hline
\end{tabular}

B
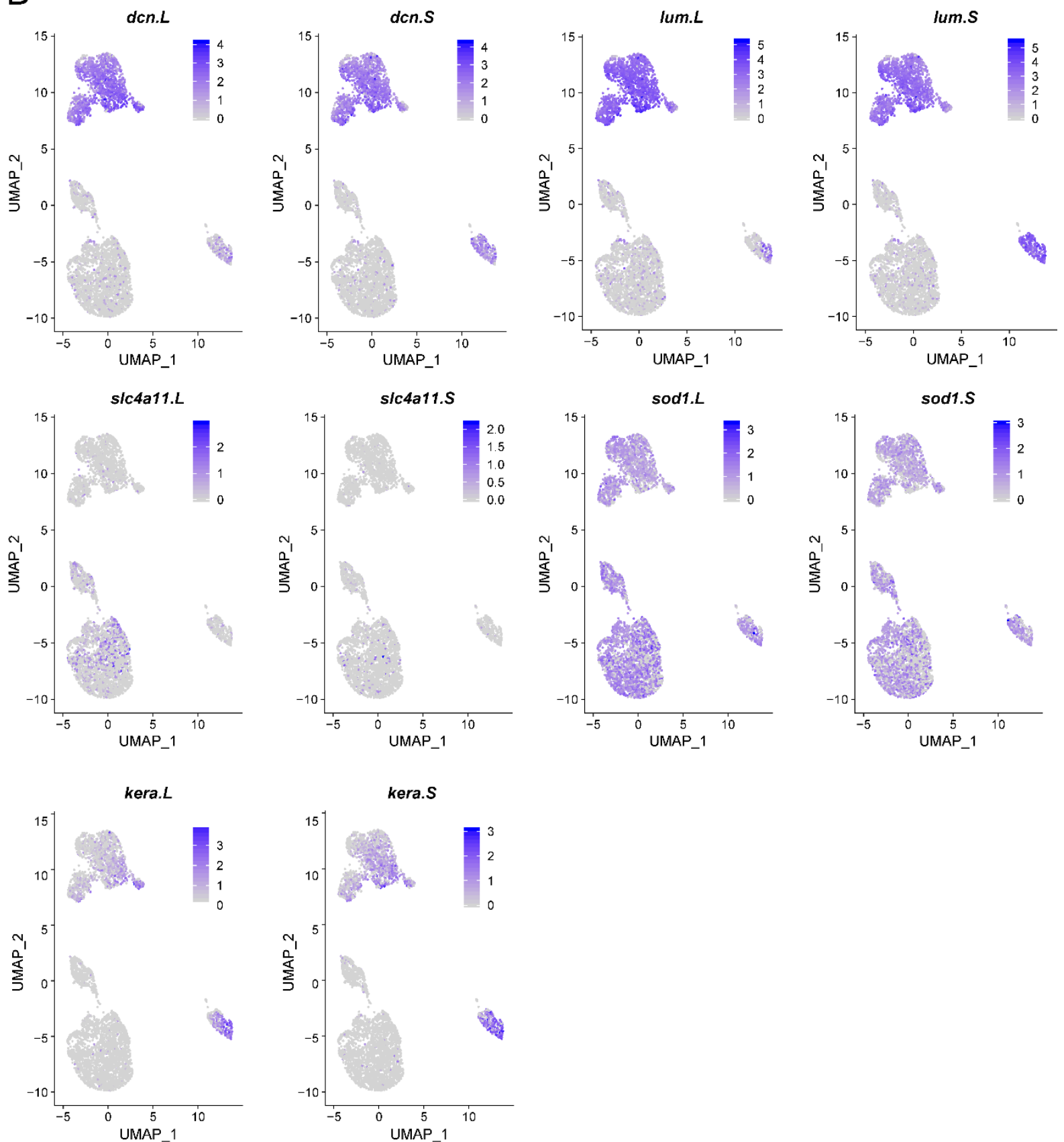

1377 Fig. S5. Identification of human corneal dystrophy gene homologues in

1378 Xenopus corneas. (A) Table showing ocular disease condition, Disease Ontology 
ID (DOID) listed in xenbase.org, Xenopus gene names, human homologue and disease literature references. (B) Feature plot of Xenopus homologues of genes associated with corneal dystrophies identified in our scRNA-seq data. Relative expression is indicated in the keys. Feature plot of krt12 is shown in Fig. 4D-E. Abbreviation: N/A: Not available

\section{REFERENCES FOR FIG. S5:} Congenital stromal dystrophy of the cornea caused by a mutation in the decorin gene. Invest Ophthalmol Vis Sci 46, 420-426.

Bredrup, C., Stang, E., Bruland, O., Palka, B. P., Young, R. D., Haavik, J., Knappskog, P. M. and Rodahl, E. (2010). Decorin accumulation contributes to the stromal opacities found in congenital stromal corneal dystrophy. Invest Ophthalmol Vis Sci 51, 5578-5582.

Chakravarti, S., Petroll, W. M., Hassell, J. R., Jester, J. V., Lass, J. H., Paul, J. and Birk, D. E. (2000). Corneal opacity in lumican-null mice: defects in collagen fibril structure and packing in the posterior stroma. Invest Ophthalmol Vis Sci 41, 3365-3373.

Han, S. B., Ang, H. P., Poh, R., Chaurasia, S. S., Peh, G., Liu, J., Tan, D. T., Vithana, E. N. and Mehta, J. S. (2013). Mice with a targeted disruption of Slc4a11 model the progressive corneal changes of congenital hereditary endothelial dystrophy. Invest Ophthalmol Vis Sci 54, 6179-6189.

Irvine, A. D., Coleman, C. M., Moore, J. E., Swensson, O., Morgan, S. J., McCarthy, J. H., Smith, F. J., Black, G. C. and McLean, W. H. (2002). A novel mutation in KRT12 associated with Meesmann's epithelial corneal dystrophy. Br J Ophthalmol 86, 729-732.

Irvine, A. D., Corden, L. D., Swensson, O., Swensson, B., Moore, J. E., Frazer, D. G., Smith, F. J., Knowlton, R. G., Christophers, E., Rochels, R., et al. (1997). Mutations in cornea-specific keratin K3 or K12 genes cause Meesmann's corneal dystrophy. Nature genetics 16, 184-187.

Kim, M. J., Frausto, R. F., Rosenwasser, G. O., Bui, T., Le, D. J., Stone, E. M. and Aldave, A. J. (2014). Posterior amorphous corneal dystrophy is associated with a deletion of small leucine-rich proteoglycans on chromosome 12. PLoS One 9, e95037.

Malhotra, D., Loganathan, S. K., Chiu, A. M., Lukowski, C. M. and Casey, J. R. (2019). Human Corneal Expression of SLC4A11, a Gene Mutated in Endothelial Corneal Dystrophies. Sci Rep 9, 9681.

Pellegata, N. S., Dieguez-Lucena, J. L., Joensuu, T., Lau, S., Montgomery, K. T., Krahe, R., Kivela, T., Kucherlapati, R., Forsius, H. and de la Chapelle, A. (2000). Mutations in KERA, encoding keratocan, cause cornea plana. Nature genetics 25, 91-95.

Roos, L., Bertelsen, B., Harris, P., Bygum, A., Jensen, H., Gronskov, K. and Tumer, Z. (2015). Case report: a novel KERA mutation associated with cornea plana and its predicted effect on protein function. BMC Med Genet 16, 40.

Udar, N., Atilano, S. R., Brown, D. J., Holguin, B., Small, K., Nesburn, A. B. and Kenney, M. C. (2006). SOD1: a candidate gene for keratoconus. Invest Ophthalmol Vis Sci 47, 3345-3351. 
1427 Table S1. List of antibodies used in this study.

1428

1429 Table S2. Sequencing metrics for scRNA-seq of corneal epithelial cells from Stage

1430 49-51 Xenopus tadpoles.

1431

1432 Table S3. Top 50 marker genes for each cell type cluster, related to Fig. 4.

1433

1434 Table S4. Enriched gene ontology (GO) terms along pseudo-time, related to Fig. 6.

1435

1436 